Review

\title{
Disruptions of Host Immunity and Inflammation by Giardia Duodenalis: Potential Consequences for Co-Infections in the Gastro-Intestinal Tract
}

\author{
James A. Cotton ${ }^{1}$, Christina B. Amat ${ }^{2,3,4}$ and Andre G. Buret ${ }^{2,3,4, *}$ \\ 1 Cumming School of Medicine, University of Calgary, Calgary, AB T2N 4N1, Canada; \\ E-Mail: jacotton@ucalgary.ca \\ 2 Department of Biological Sciences, University of Calgary, Calgary, AB T2N 1N4, Canada; \\ E-Mail: cb.amat@ucalgary.ca \\ 3 Inflammation Research Network, University of Calgary, Calgary, AB T2N 1N4, Canada \\ 4 Host-Parasite Interactions, University of Calgary, Calgary, AB T2N 1N4, Canada \\ * Author to whom correspondence should be addressed; E-Mail: aburet@ucalgary.ca; \\ Tel.: +403-220-2817; Fax: +403-289-9311.
}

Academic Editor: Kris Chadee

Received: 23 September 2015 / Accepted: 5 November 2015 / Published: 10 November 2015

\begin{abstract}
Giardia duodenalis (syn. G. intestinalis, or G. lamblia) is a leading cause of waterborne diarrheal disease that infects hundreds of millions of people annually. Research on Giardia has greatly expanded within the last few years, and our understanding of the pathophysiology and immunology on this parasite is ever increasing. At peak infection, Giardia trophozoites induce pathophysiological responses that culminate in the development of diarrheal disease. However, human data has suggested that the intestinal mucosa of Giardia-infected individuals is devoid of signs of overt intestinal inflammation, an observation that is reproduced in animal models. Thus, our understanding of host inflammatory responses to the parasite remain incompletely understood and human studies and experimental data have produced conflicting results. It is now also apparent that certain Giardia infections contain mechanisms capable of modulating their host's immune responses. As the oral route of Giardia infection is shared with many other gastrointestinal (GI) pathogens, co-infections may often occur, especially in places with poor sanitation and/or improper treatment of drinking water. Moreover, Giardia infections may modulate host immune responses and have been found to protect against the development of diarrheal disease in developing countries. The following review summarizes our current understanding of the immunomodulatory
\end{abstract}


mechanisms of Giardia infections and their consequences for the host, and highlights areas for future research. Potential implications of these immunomodulatory effects during GI co-infection are also discussed.

Keywords: Giardia duodenalis; host-parasite interactions; diarrheal disease; inflammation; immunomodulation

\section{Introduction}

Infections caused by the protozoan parasite Giardia duodenalis (syn. G. intestinalis, G. lamblia) are a major cause of waterborne diarrheal disease worldwide, and are estimated to cause $\sim 280$ million infections annually [1]. However, the advent of molecular assays with higher sensitivity for Giardia trophozoites and cysts suggests this number may be underestimated [2,3]. This parasite has long been overlooked for its ability to cause diarrheal disease, and it was not until the 20th century that it was definitively identified as a causative agent of infectious diarrheal disease [4]. Giardia is now included on the WHO's Neglected Disease Initiative [5], and research on Giardia appears to be increasing [6]. At the height of infection, Giardia trophozoites induce pathophysiological processes that result in a malabsorptive diarrheal disease (reviewed in [7]). Symptoms classically associated with Giardiasis include diarrhea, abdominal pain, nausea, vomiting, and anorexia. However, infected individuals can also develop extra-intestinal and post-infectious complications [8,9]. Chronic extraintestinal sequelae may affect the joints, the skin, the eyes, and even the central nervous system, and the mechanisms are unknown [8,9]. For reasons that remain obscure, Giardia infections cause a spectrum of symptoms ranging from asymptomatic carriage through to chronic diarrheal disease [10]. Although chronic Giardia infection tends to occur in immunocompromised individuals, it has been reported in patients without obvious immunodeficiency (reviewed in [10]). In addition, asymptomatic infection has been observed in developed countries following re-infection with the same isolate [11]. Giardia is currently subdivided into eight distinct genetic assemblages labelled as assemblage " $\mathrm{A}$ " through " $\mathrm{H}$ " $[12,13]$. Humans are susceptible to infection from assemblage "A" and "B" isolates. Some studies have suggested that symptom development may in part be assemblage-dependent, but results are largely inconclusive [14-18]. However, in vivo studies in mice have demonstrated differences in the pathogenicity of assemblage A and B isolates [19], and genomic analysis of assemblage A and B isolates indicates substantial disparity between the two groups [20,21]. This has led to the proposition that assemblage "A" and "B" Giardia isolates are actually unique Giardia species, a topic of ongoing debate in the scientific literature [20,22].

Our understanding of the pathophysiology and immunity in giardiasis is drastically improving, yet discrepancies in study results persist and much remains to be learned [23-26]. Several parasites are known to affect various aspects of their host's pro-inflammatory responses [27,28], and recent findings indicate that Giardia actively modulates host inflammatory responses (as referenced below). This is particularly important when considering that this parasite is often found in association with a variety of pro-inflammatory gastrointestinal (GI) pathogens. The purpose of this review is to summarize our current understanding surrounding the immunomodulatory mechanisms of Giardia and discuss potential consequences of this phenomenon during GI co-infection. 


\section{Does Giardia duodenalis Induce Pro-Inflammatory Responses?}

The GI mucosal barrier is comprised of two main components: a secreted mucus layer and the intestinal epithelium. This structure restricts luminal contents, including various exogenous and endogenous antigens, from contacting underlying host tissues and, subsequently, inducing GI pro-inflammatory responses (reviewed in [29,30]). Dysfunction of the GI mucosal barrier is observed in chronic GI inflammatory states, such as Crohn's disease, and contributes to disease progression [31,32]. Moreover, a broad variety of GI pathogens induce GI barrier dysfunction during infection [33,34]. It has been well established that Giardia infections cause intestinal barrier dysfunction via a variety of mechanisms, including activation of myosin light chain kinase and increased rates of intestinal epithelial apoptosis [35-39]. At the height of infection, parasite numbers exceed $10^{6}$ trophozoites per centimetre of gut; coupled with increases in intestinal permeability, it is possible that the presence of copious amounts of exogenous parasitic material could induce pro-inflammatory intestinal responses via translation to subepithelial spaces. In addition, it has recently been suggested that certain G. duodenalis isolates may be capable of invading into host tissues in in vivo gerbil models [40]. Despite this, evidence supporting the development of any overt inflammatory response is lacking, and human studies and experimental research have produced conflicting results. Histological analysis of Giardia-infected individuals and in vivo Giardia muris infections shows small intestinal mucosal tissues are devoid of signs of significant inflammation [41-44]. Small increases in intra-epithelial lymphocyte numbers and mast cell hyperplasia post-infection have been observed [45]. Microarray analysis of jejunal tissues from assemblage E-infected cattle demonstrated downregulation of genes associated with inflammatory and immune responses, as well as immune cell migration; this was associated with increased expression of the anti-inflammatory transcription factor peroxisome proliferation activation receptor $\gamma(\operatorname{PPAR} \gamma)$ [46]. Moreover, co-incubation in vitro of intestinal epithelial monolayers and assemblage A Giardia trophozoites does not produce pro-inflammatory cytokines and/or chemokines [47,48]. Rather, microarray analysis from studies in vitro demonstrated that assemblage A G. duodenalis induces a chemokine profile that is different from the host responses commonly seen with other GI pathogens, whereby parasites significantly increased mRNA levels of CCL2, CCL20, and CXCL1-3 [49]. In children populations from developing countries, Giardia infections also have been found to reduce the incidence of diarrheal disease and fever, and decrease serum C-reactive protein (CRP) levels, which is a common marker of inflammation [50]. Together, the data available to date would indicate that Giardia infections fail to induce, and perhaps downregulate, factors associated with intestinal inflammatory responses within its hosts.

However, findings from some human studies and experimental evidence suggest that Giardia infections may induce pro-inflammatory intestinal responses. Subsets of human patients with chronic assemblage $\mathrm{B}$ infection were shown to develop microscopic duodenal inflammation and displayed elevated fecal calprotectin levels [51]. Experimental infections in vivo with G. duodenalis assemblage B have been associated with post-infectious neutrophil (polymorphonuclear leukocyte, PMN) infiltration in the terminal ileum [52] or even more robust intestinal inflammatory responses [53]. Excretory/secretory products from these assemblage $\mathrm{B}$ trophozoites activated pro-inflammatory mitogen activated protein kinase (MAPK) and nuclear factor of $\kappa \mathrm{B}(\mathrm{NF}-\kappa \mathrm{B})$ signaling pathways in intestinal epithelial monolayers and produced pro-inflammatory cytokines and chemokines, including tumor necrosis factor $\alpha$ (TNF- $\alpha$ ) and the potent PMN chemoattractant interleukin-8 (CXCL8) [54]. In addition, reports examining human 
patients [55,56] and ruminants [57] suggested that at least some Giardia infections may cause eosinophilia; this was also shown in in vivo infections whereby Giardia assemblage B H3 infections [58] or parasite excretory/secretory products [59] caused intestinal recruitment of eosinophils. It is interesting that in vivo and in vitro experimental data suggest assemblage B isolates induce intestinal pro-inflammatory responses, while similar observations have not been demonstrated for assemblage A isolates, or with Giardia muris infections in vivo. Some reports correlate assemblage B infections with more severe symptomatology, while others have suggested the same for assemblage A infections [14-17]. More research is needed to determine whether assemblage $\mathrm{B}$ infections may indeed induce intestinal inflammatory responses and more severe diarrheal disease. The differences between the pro-inflammatory capabilities of assemblage A and B Giardia isolates warrant further investigation.

\section{Polymicrobial GI Infections Involving Giardia}

The above observations that Giardia infections may or may not induce pro-inflammatory intestinal responses also need to be considered in the context of GI co-infections. Giardia infections occur upon ingestion of contaminated food or water, or directly via the fecal-oral route (reviewed in [60]). This method of acquisition is common to various GI pathogens, and, therefore, can easily result in polymicrobial GI infections in the appropriate setting. Due to poor hygiene and lack of appropriate water treatment facilities, polymicrobial infections are more frequently observed in developing countries but can also occur within developed countries [61,62]. Infections are more likely to cause symptomatic infection in individuals living in developed countries compared to those living in developing countries [63,64]. Indeed, Giardia infections have been reported concurrently with pro-inflammatory pathogens such as Helicobater pylori, Vibrio cholera, enteropathogenic Escherichia coli, norovirus, and rotavirus [65-68], and others have found Giardia infections in association with Ascaris sp., Cryptosporidium sp., Clostridium difficile, and Salmonella sp. [69-71]. However, our knowledge of polymicrobial GI infections and intestinal inflammatory responses involving Giardia is poorly understood, and, to date, much evidence is anecdotal. Several human studies suggest that Giardia infections may protect against the development of diarrheal disease and, potentially, the development of intestinal inflammatory responses [72]. Tanzanian children infected with Giardia were shown to have reduced incidence of diarrheal disease and fever, and lower serum C-reactive protein levels [50]. However, this study did not look for the presence of polymicrobial GI infections. Giardia infections in humans have also been associated with other GI pathogens or identified in control patients not experiencing diarrhea [67]. Giardia infections may reduce the severity of symptoms associated with rotavirus infection [68], yet separate studies have suggested that Giardia infections enhanced the severity of rotavirus infection [73]. To date, we have no scientific explanation for these observations. Apart from a single in vivo study showing acute intestinal infection with Trichinella spiralis increases host susceptibility to Giardia GS/M infection [74], in vivo polymicrobial infections involving Giardia parasites have not been examined.

\section{Giardia and Immunomodulation}

Accumulating experimental evidence suggests that Giardia infections are also capable of modulating pro-inflammatory responses to other stimuli via several mechanisms. Observations that Giardia infections can protect against the development of diarrheal disease are consistent with the immunomodulatory 
capabilities of the parasite. Indeed, acute GI inflammatory responses represent a collection of cellular and humoral effector responses and involve a variety of different cell types and mediators; several of these have been shown to contribute to the development of diarrheal disease. For example, infection with enterohaemorrhagic E. coli causes chloride hypersecretion, a major driving force for diarrheal disease, via mechanisms that require PMN infiltration [75]. Research has demonstrated that certain Giardia infections are capable of attenuating recruitment of pro-inflammatory leukocytes and decreasing nitric oxide (NO) production (as referenced below). In addition, evidence is accumulating that Giardia infections may modulate other pro-inflammatory events. However, these mechanisms have not been fully characterized. The following sections will describe the immunomodulatory mechanisms of Giardia and describe how this may result in the attenuation of diarrheal disease during GI co-infection.

\subsection{Giardia and the Intestinal Mucus Layer}

The entire GI tract is lined with a layer of mucus of varying thickness with a structural backbone comprised of mucin glycoproteins dissolved in luminal water. In the colon, this layer can be further subdivided into two separate layers: a dense, inner mucus layer largely devoid of bacterial populations and an outer, loosely packed outer layer containing various bacterial populations [76,77]. In the intestinal tract, the primary mucus constituent is the mucin-2 (MUC2) protein [76-78]. Preliminary research in our lab has demonstrated in vivo Giardia assemblage B GS/M isolate infections in mice damages the small intestinal mucus layer by degrading the MUC2 protein and inducing the hypersecretion of mucus in the small intestine and colon, resultantly leading to mucin depletion from goblet cells; this culminated in a weakened mucus layer and facilitated disease (unpublished data). Furthermore, studies monitoring mucus disruption during in vivo Giardia GS/M infections have observed an increase in bacterial translocation across the epithelial barrier, but this was not associated with an increase in pro-inflammatory markers at the point of acute infection [52]. Separate in vivo studies have demonstrated that pro-inflammatory enteropathogens, such as H. pylori, Entamoeba histolytica, and Trichuris muris, alter the mucus layer and this contributes to the initiation or exacerbation of GI disease [79-82]. Similarly, modulation or aberrant assembly of the mucus layer is often associated with intestinal inflammation and increased expression of pro-inflammatory cytokines including interleukin (IL)-1 $\beta$, IL-4, IL-6, CXCL8 IL-13, and TNF- $\alpha$ [83-86]. Finally, in vivo studies using mice devoid of Muc2 have revealed that the mucus layer plays an important role in protection against GI infection from pro-inflammatory enteropathogens, such as E. histolytica and T. muris, and deletion of this gene results in exacerbated intestinal inflammatory responses [87-89]. Similarly, disruption or aberrant expression of MUC2 has been observed in patients with chronic intestinal inflammatory disorders, such as ulcerative colitis [90-92]. Collectively, these results demonstrate that disruption of the intestinal mucus layer is largely associated with GI inflammation. It remains to be determined why disruption of the mucus layer during Giardia infections fails to elicit pro-inflammatory intestinal responses. Moreover, it remains to be seen how Giardia co-infections may alter host pro-inflammatory responses and/or alter susceptibility to co-infecting GI pathogens. 


\subsection{Giardia and Neutrophil Recruitment}

The tissue accumulation of polymorphonuclear leukocytes or neutrophils (PMNs) is a hallmark of numerous bacterial, viral, and parasitic GI infections. PMNs are myeloid-derived innate immune cells essential to host defence against a variety of bacterial and fungal pathogens, and they possess various anti-microbial mechanisms, including the ability to phagocytose infectious agents, secrete anti-microbial proteases, and release neutrophil extracellular traps (NETs) (reviewed in [93]). In the absence of pro-inflammatory stimuli, PMNs are kept in a non-activated state within the bone marrow and circulation. During an acute inflammatory response, increased expression and production of PMN chemoattractants promotes PMN activation and recruitment into tissues, including the GI tract (reviewed in [94,95]). Certain PMN chemoattractants are capable of inducing the transepithelial migration of PMNs; this process occurs following PMN contact with the basolateral surface of the intestinal epithelium and results in functional changes to both PMNs and intestinal epithelial cells (IECs) [96]. Importantly, PMN infiltration can induce pathophysiological responses that result in water and solute loss and, hence, diarrheal disease, and in vivo and in vitro experiments have suggested this may involve PMN-mediated intestinal barrier dysfunction and/or anion secretion [75,97-99]. Collectively, these results demonstrate the importance PMNs have in contributing to diarrheal disease.

Recent studies have shown that Giardia infections may attenuate intestinal PMN recruitment. Notably, these observations have been recorded with assemblage A, the genotype that has been postulated not to induce overt intestinal pro-inflammatory responses (see above). For example, Giardia assemblage A decreased granulocyte infiltration and cytokines and chemokines involved in PMN recruitment after intra-rectal instillation of pro-inflammatory Clostridium difficile toxin $\mathrm{A} / \mathrm{B}$; these effects were not observed with in vivo Giardia assemblage B GS/M infections [100]. This study was also the first to demonstrate that co-incubation of Giardia trophozoites with inflamed colonic mucosal biopsy tissues from patients with active Crohn's disease decreased supernatant levels of numerous pro-inflammatory mediators, including those involved in PMN recruitment [100]. Further studies went on to identify potential immunomodulatory molecules involved in this process. The findings demonstrated that assemblage A Giardia cathepsin B (catB) cysteine proteases degraded CXCL8 induced by pro-inflammatory interleukin-1 $\beta$, or by Salmonella enterica serovar Typhimurium, and attenuated CXCL8-induced PMN chemotaxis; these effects were not observed with assemblage B GS/M trophozoites at early time points and, potentially, occur via different mechanisms [101]. These studies highlight a hitherto unidentified anti-inflammatory capability for Giardia infections and, more specifically, Giardia catB proteases. Another recent study shows that these catB cysteine proteases may also be implicated in the degradation of epithelial villin [102]. Otherwise, very little is known about the function of Giardia cathepsin cysteine proteases (Box 1). 
Box 1. Giardia cathepsin cysteine proteases.

The term cathepsin was initially used to describe proteases active in a lightly acidic environment. However, as genome sequencing of different species has progressed, it has become evident that not all cathepsin-like proteases are active at an acidic $\mathrm{pH}$. Cathepsin cysteine proteases consist of a catalytic diad of a cysteine and a histidine residue, whereby the histidine residue donates an electron to the cysteine residue to make it a stronger nucleophile (reviewed in [103]). Cathepsin cysteine proteases are divided down into two superfamilies: the cathepsin-L(catL)-like and the cathepsin-Blike superfamilies. Cathepsin B-like cysteine proteases contain a unique $\sim 20$-amino-acid insertion referred to as the occluding loop; this structure allows the protease to function as an endo- and exopeptidase. The Giardia genome contains genes for numerous catB and catL proteases [104]. Interestingly, the Giardia catB protein appears to lack the occluding loop present in human catB [105]. Prior to an immunomodulatory role for Giardia catB proteases, very little was known about Giardia cathepsin cysteine proteases. Indeed, it was demonstrated that these factors were upregulated following exposure to in vitro intestinal epithelial monolayers and they played a role in parasite encystation and excystation [106]. Ongoing research has demonstrated that Giardia cathepsin-like cysteine proteases induce the myosin light chain kinase (MLCK)-mediated breakdown of cytoskeletal villin [102]. Future studies should continue to elucidate the role of Giardia cathepsin cysteine proteases in disease and their regulation within the parasite For example, Toxoplasma gondii catB proteases actually require catalytic activation via the parasite's catL proteases [107]. It remains to be seen whether similar effects are observed with Giardia catB proteases.

The construction of preliminary phylogenetic trees using ClustalW [108] for Giardia cathepsin B (catB) (Figure 1) and cathepsin L (catL) (Figure 2) cysteine proteases of sequenced parasite isolates used in our above study (see Cotton et al [101]) suggests certain parasite isolates may contain unique catB proteases; this may explain differences in the ability of parasites to degrade CXCL8. However, it should be noted that sequencing of Giardia genomes is incomplete and, therefore, construction of these phylogenetic trees requires re-analysis following their completion. These data may lend credence to the hypothesis that certain Giardia isolates may possess unique immunomodulatory cathepsin cysteine proteases. The utilization of these phylogenetic trees in association with the Cre/loxP system in Giardia trophozoites [109] may aid in the identification of immunomodulatory functions of cathepsin cysteine proteases. In addition, it remains to be determined whether Giardia catB proteases modulate or degrade other cytokines or chemokines, as indicated by the above observations that $G$. duodenalis trophozoites reduce tissue concentrations of numerous cytokines and chemokines released from inflamed colonic mucosal biopsy tissues [100]. Indeed, other parasites use cathepsin-like cysteine proteases to modulate host immune responses via the alteration of cytokines or chemokines (reviewed in [105,110]). For example, Entamoeba histolytica cysteine proteases alter interleukin-18 [111] and the end-target PMN chemokine C5a [112]. As a result, future studies could investigate other pro-inflammatory mediators targeted by Giardia cathepsin cysteine proteases. 


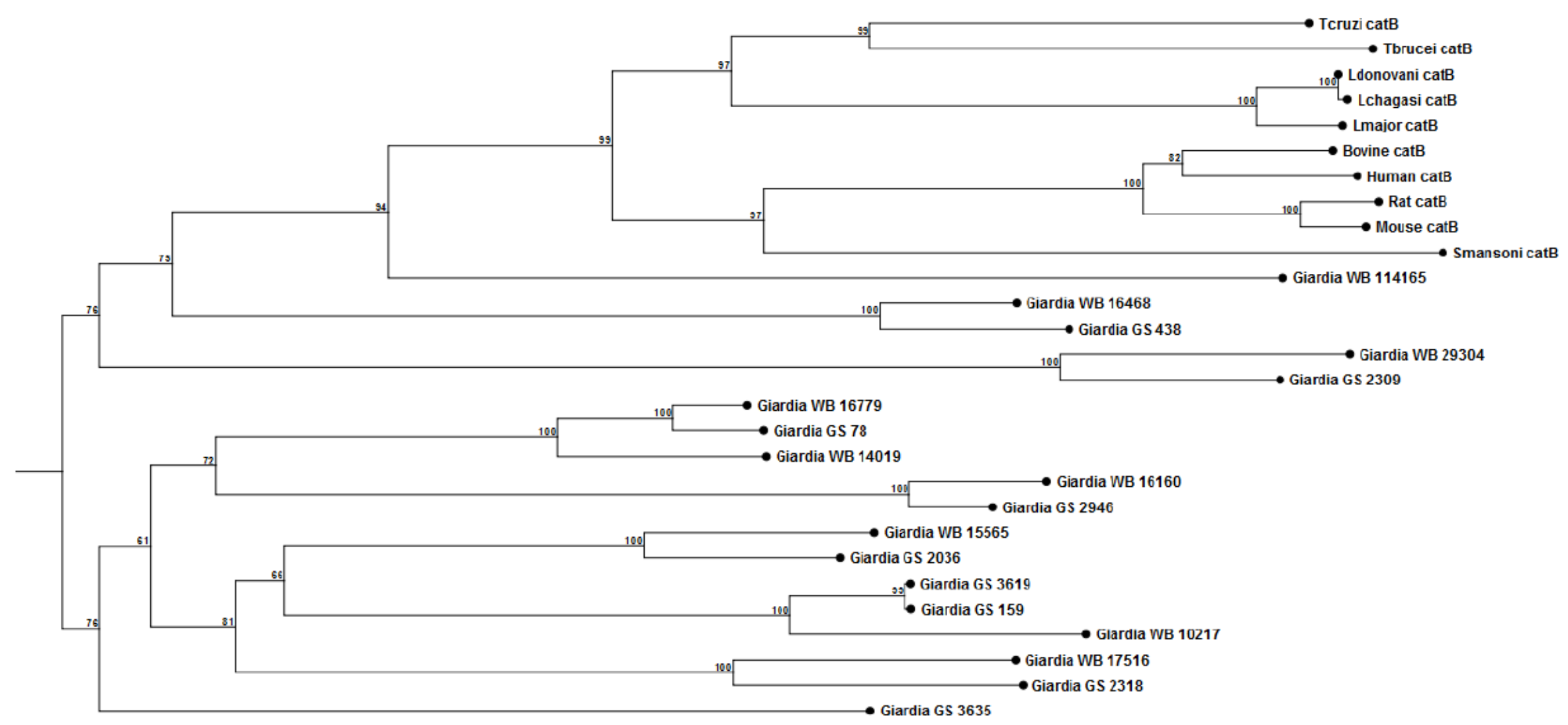

0.350

Figure 1. Phylogenetic tree and bootstrap values of Giardia WB and Giardia GS/M cathepsin B cysteine proteases. Proteases were compared against human, bovine, mouse, rat, Schisotoma mansonii, Leishmania major, L. donovani, L. chagasi, Trypanosoma brucei, and T. cruzi catB cysteine proteases. Alignment and phylogenetic trees of cathepsin B cysteine proteases were assembled using ClustalW and CLC Sequence Viewer (Qiagen). These observations indicate that Giardia isolates may contain unique catB cysteine proteases. 


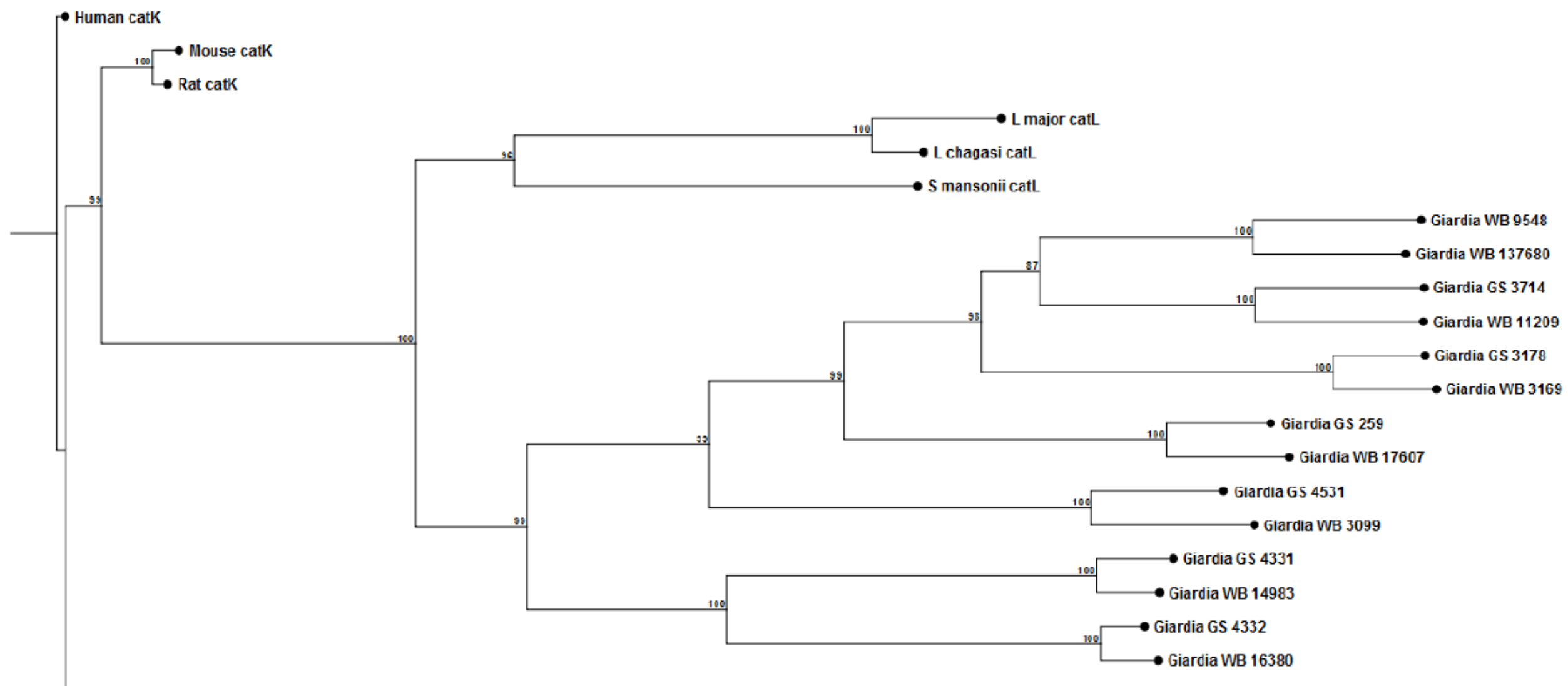

Figure 2. Phylogenetic tree and bootstrap values of Giardia WB and Giardia GS/M cathepsin L cysteine proteases. Proteases were compared against human, bovine, mouse, rat, Schisotoma mansonii, Leishmania major, and L. chagasi catL cysteine proteases. Alignment and phylogenetic trees of cathepsin L cysteine proteases were assembled using ClustalW and CLC Sequence Viewer (Qiagen). 
CXCL8 is primarily secreted basolaterally by IECs to recruit extravasated PMNs to the basolateral membrane of the intestinal epithelium so subsequent signals can, if necessary, promote PMN transepithelial migration [113-115]. Therefore, the immunomodulatory capability of Giardia cathepsin cysteine proteases implies that these must be delivered to the basolateral surface of the intestinal epithelium. In the studies discussed above, apical-to-basolateral translocation of cysteine proteases occurred when Giardia trophozoites and Caco-2 monolayers were co-incubated with Salmonella enterica serovar Typhimurium [101]. These results may also suggest that delivery of immunomodulatory cathepsin cysteine proteases can be facilitated by the presence of $S$. Typhimurium. Another study demonstrated that co-incubation of Giardia trophozoites, intestinal epithelial monolayers, and macrophage-like IC-21 cells in vitro resulted in basolateral attenuation of CXCL8 [116]; this study did not investigate causal mechanisms. As macrophages are known to increase intestinal epithelial permeability [117], more research is needed to assess whether and how the interaction between parasites, IECs, and immune cells may facilitate the apical-to-basolateral migration of immunomodulatory Giardia catB proteases.

\section{Modulation of Neutrophil Recruitment and Co-Infections}

It is well established that individuals with genetic mutations resulting in defective PMN function are highly susceptible to bacterial and fungal infection [118-120], and similar events have been observed during certain experimental GI infections. For example, in vivo depletion of PMNs increases mortality due to $C$. difficile infection $[121,122]$, while intestinal PMN influx reduces pathogen burdens from the attaching and effacing pathogen Citrobacter rodentium and protects against pathogen-induced diarrheal disease [123]. In contrast, other reports indicate that GI inflammatory responses and PMN infiltration may increase susceptibility to GI infection, and it has been postulated that the development of GI inflammatory responses disrupts resident microbiota populations, which in turn aides pathogen colonization [124]. Research has shown that $S$. Typhimurium outcompetes the host's resident microbiota during intestinal inflammatory responses to facilitate its colonization [125-128]. Similarly, attenuated PMN recruitment in vivo reduces colonization by Campylobacter jejuni [129] and C. rodentium [130]. In addition, PMN recruitment has been shown to aggravate experimental colitis [131]; this may occur via the PMN's ability to induce protective responses within IECs via the induction of hypoxia-inducible factor (HIF) [132] or the secretion of interleukin-22 (IL-22) [133]. In this context, the above observations that certain Giardia infections modulate PMN recruitment require further investigation in the context of GI co-infection. Specifically, experiments need to ascertain whether Giardia-mediated modulation of PMN recruitment into intestinal tissues is of benefit or detriment to a host co-infected with another GI pathogen. This may, ultimately, be dependent upon the co-infecting GI pathogen.

\subsection{Giardia and L-Arginine}

L-arginine is utilized for a variety of cellular processes and signaling events; it is incorporated into various proteins and is a precursor substrate for various other molecules [134]. During homeostasis, L-arginine levels are maintained by endogenous production in the intestine and kidneys [134]. Several pathogens have been found to compete with their host for L-arginine during infection, and, therefore, exogenous sources of the amino acid are required in these instances [135]. Indeed, L-arginine is a 
primary source of energy for Giardia trophozoites [136], and restoration of host arginine levels via ornithine supplementation during oral rehydration therapy has been proposed to be beneficial in the treatment of symptomatic giardiasis [137]. Nitric oxide (NO) is also important in prompt parasite eradication in in vivo $G$. duodenalis infections in mice [138-140]. Following exposure to intestinal epithelial monolayers, Giardia trophozoites quickly upregulate the expression of two enzymes: arginine deiminase and ornithine carbomyl transferase (OCT). These enzymes are important in parasite arginine metabolism and effectively outcompete host enzymes [141,142]. Depletion of L-arginine levels has been shown to affect multiple cellular processes and results in the modulation of host immune responses; this includes decreased production of nitric oxide, modulation of T-cell and dendritic cell function, and cessation of intestinal epithelial proliferation (discussed below).

Parasite Arginine Consumption Inhibits NO Production

NO production is initiated by the enzymatic conversion of L-arginine into L-citrulline by three nitric oxide synthase (NOS) isoforms: neuronal NOS (nNOS or NOS1), inducible NOS (iNOS or NOS2), or endothelial NOS (eNOS or NOS3) [143]. In IECs, NO is largely produced by iNOS, and is upregulated following exposure to various host- or pathogen-derived pro-inflammatory stimulatory processes $[144,145]$. NO has anti-microbial activity against numerous bacterial and parasitic pathogens [146-148], and in vitro experiments have demonstrated NO and its end-products are cytostatic to Giardia trophozoites and inhibit their encystation and excystation [48,141]. Exposure to parasites resulted in the initial upregulation of iNOS mRNA in in vitro intestinal epithelial monolayers [149], but human studies suggest that infection may also result in the downregulation of iNOS expression [150]. L-arginine consumption by Giardia trophozoites prevents the IEC-mediated production of iNOS-mediated NO production [48,141]. Moreover, assemblage A and B Giardia trophozoites produce a flavohemoglobin capable of degrading NO and attenuating T-cell proliferation [149]. Collectively, these results demonstrate that Giardia trophozoites possess multiple mechanisms aimed at decreasing their exposure to NO.

It remains to be determined how the consumption of L-arginine and the concomitant loss of NO during Giardia infections may contribute to the modulation of host immune responses and/or susceptibility to co-infecting GI pathogens. Indeed, NO has multiple roles in modulating host immune responses and targeting GI pathogens. For example, animals deficient in iNOS are highly susceptible to infection with Listeria monocytogenes [151]. Separately, in vivo models of colitis have shown that the activation of iNOS and the subsequent NO production contribute to the resolution of inflammation [152] and attenuate pro-inflammatory responses [153]. In contrast, genetic deletion or pharmacological inhibition of iNOS has been shown to protect against dextran sodium sulfate (DSS)-induced colitis [154,155]. These results suggest that the immunomodulatory capacity of iNOS and NO may depend on the model of GI inflammation. Additional experiments are required to determine how the Giardia-mediated inhibition of NO production may, potentially, modulate host inflammatory responses and/or susceptibility to GI infection. It has also been demonstrated that NO production during GI infection can induce anion secretion and, therefore, cause diarrheal disease [156]. However, NO has also been shown to inhibit intestinal trafficking of the cystic fibrosis transmembrane conductance regulator (CFTR) protein in intestinal epithelial monolayers and, therefore, may inhibit anion secretion [157]. As numerous GI 
pathogens induce NO, it is possible that Giardia infections protect against the development of diarrheal disease via this mechanism. However, additional studies are required to confirm this hypothesis.

\subsection{Intestinal Epithelial Cell Death}

Changes in intestinal epithelial cellular proliferation are essential responses to GI infection and facilitate the removal of damaged and/or pathogen-infected cells; however, GI pathogens can alter the kinetics of epithelial cell death and turnover to facilitate their colonization and subsequent invasion (reviewed in [158-161]). For example, enteroinvasive Escherichia coli, Salmonella sp., and Shigella sp. initially suppress and, subsequently, induce various forms of intestinal epithelial cell death to facilitate replication and dissemination within their host, respectively; this can be associated with the activation of pro-survival pathways such as the NF-кB pathway [162-166]. Giardia infections can inhibit intestinal epithelial proliferation and, subsequently, induce intestinal epithelial apoptosis; however, the pathophysiological processes may differ from those of other GI pathogens discussed above. L-arginine is involved in cellular proliferation via its conversion into polyamines [167], and Giardia arginine deiminase-mediated consumption of arginine has been associated with the inhibition of in vitro IEC proliferation [137]; this consumption was proposed to reduce intestinal epithelial cell turnover and create a more stable environment for the parasite [137]. Contrastingly, increases in intestinal epithelial proliferation have been reported in in vivo G. duodenalis GS/M mouse infections [168]; therefore, it remains to be determined whether the consumption of arginine by parasites inhibits IEC proliferation. Other reports have demonstrated that Giardia trophozoites induce IEC apoptosis via the activation of cysteinyl asparate proteases (caspases) through mechanisms that remain incompletely understood [35,37,39]. However, it remains to be determined how these pathophysiologic processes induced by Giardia potentially modulate host immune responses and their interaction during GI co-infections. It is possible that Giardia-mediated upregulation of intestinal epithelial cell death may increase the expulsion of co-infecting GI pathogens. It is also currently unknown whether Giardia trophozoites modulate pro-inflammatory signaling cascades, such as the NF- $\kappa$ B pathway, in IECs to delay the induction of cell death. Caspase proteins inactivate or degrade various proteins associated with the NF- $\mathrm{KB}$ signaling cascade [169-171]. Research needs to determine whether Giardia may degrade pro-inflammatory transcription factors, thereby preventing bacterial pathogens from initially inhibiting cell death cascades within IECs to allow for their replication prior to dissemination into deeper host tissues.

\subsection{Dendritic Cells}

Dendritic cells (DCs) are essential to the induction of adaptive immune responses and/or tolerance. Following their activation, DCs become immunogenic antigen-presenting cells capable of promoting the expansion and differentiation of naïve T-cells into effector T-cells via a three-step process. DCs consume and process antigen, couple it to major histocompatibility complexes (MHC), and, subsequently, present this to naïve T-cell populations; in addition, DCs also use co-stimulatory molecules, such as CD80 and CD86, and produce mediators, such as cytokines, to influence the differentiation of naïve $\mathrm{T}$ cells in various subsets (reviewed in [172,173]). Within the GI tract, especially in the distal small intestine, DCs directly sample luminal contents via the extension of dendrites between adjacent IECs [174,175]. Research to date has produced conflicting results on how Giardia trophozoites affect DC activation and 
their ability to induce and/or modulate effector immune responses. The co-incubation of Giardia assemblage B GS/M trophozoite extracts and murine bone marrow-derived DCs in vitro resulted in the upregulation of co-stimulatory CD40, and to a lesser extent, CD80 and CD86; moreover, these extracts altered DC responses to toll-like receptor (TLR) ligands, whereby parasites reduced the expression of MHC Class II, CD80, and C86, decreased the secretion of IL-12, and enhanced IL-10 production via activation of the PI3K pathway [176]. In contrast, separate experiments found that the Giardia homolog of immunoglobulin protein (BiP) triggered the expression of MHC Class II molecules and concomitantly resulted in the secretion of TNF $\alpha$, IL-12, and IL-6 via several pro-inflammatory signaling cascades in in vitro murine dendritic cells [177]. Experiments using assemblage A Giardia WB trophozoites demonstrated that the parasite decreases the production of IL-12p40, IL-12p70, and IL-23 by human DC in vitro and the expression of co-stimulatory molecules and human leukocyte antigen (HLA) DR (HLA-DR) while enhancing the production of anti-inflammatory IL-10; interestingly, DCs incubated with these parasites and concurrently exposed to TLR2 ligands enhanced IL-12p40, IL-23, and IL-10 production [178]. Separately, arginine depletion induced by the same parasite isolate was shown to reduce the surface expression of CD83 and CD86, decrease the secretion of IL-10 and IL-12p40, and enhance TNF $\alpha$ production in in vitro human DCs [179]. In other experiments, the in vitro co-incubation of bovine DCs and a mixture of Giardia assemblage A and E trophozoites resulted in elevated MHC Class II molecules, TGF- $\beta$, TNF $\alpha$, IL-10, and IL-4; these DCs are able to induce T-cell proliferation [180]. Collectively, these results demonstrate that Giardia trophozoites are capable of modulating DC cell function. Future studies should compare and contrast DC function and activation following exposure to different Giardia isolates and assemblages.

\subsection{Macrophages}

Ongoing research has demonstrated these macrophages change their function based on endogenous and exogenous stimuli within the local tissue environment; this also results in the altered expression of several surface markers and leads to their classification into subgroups, commonly known as M1 and M2 macrophages [181,182]. M1 macrophages have been labelled as "inflammatory macrophages" that produce various inflammatory mediators and molecules, such as TNF $\alpha$, whereas the M2 macrophage phenotype is often thought to antagonize host pro-inflammatory responses, including the production of nitric oxide, and can result in the expression of Arginase-1 [183]. However, current research suggests these cell types do not exist as distinct entities, but rather as a continuum of differing phenotypes [184]. To date, very little research has examined how Giardia infections modulate macrophage phenotypes during infection, and only one study has shown that in vivo Giardia assemblage B infections result in the accumulation of macrophages positive for both NOS2 and Arginase-1 [185]. Additional research is required in order to investigate how Giardia infections induce this unique macrophage phenotype, and, moreover, whether these macrophages are observed during human Giardia infections or in vivo assemblage A or Giardia muris infections. Future studies are also required to assess whether a Giardia-induced switch to macrophage phenotype, if present, may alter susceptibility to GI co-infection. As individuals with mutations in cytokines associated with M1 macrophage polarization are more susceptible to infection by numerous microorganisms [186,187], Giardia-induced changes to macrophage phenotypes may significantly affect susceptibility to a variety of infections. For example, the intracellular replication 
of $S$. Typhimurium is greatly impaired in monocyte-derived macrophages with an M1 phenotype [188]. Moreover, macrophage Arginase-1 expression has been found to limit helper Th2-mediated immune responses and fibrosis during in vivo Schistosoma mansonii infection [189]. Collectively, these studies highlight the need for additional research examining the interaction between Giardia and host macrophages.

\section{Giardia and Distant Site Co-Infections}

Although this review is focused on the immunomodulatory effects of Giardia in GI tissues and its potential effects on host responses during GI co-infection, it is important to also consider whether this parasite may alter host immune responses to microbial pathogens at distant organ sites. Such effects have been observed with soil-transmitted helminth infections modulating host immune responses to various pathogens, including Plasmodium sp., Mycobacterium tuberculosis, and human immunodeficiency virus (HIV) (reviewed in [190]). It is possible that the immunomodulatory mechanisms of Giardia may also modify host responses to other pathogens. Human studies have demonstrated that Giardia infections reduce serum levels of serum CRP [50], thereby indicating that these infections are capable of modulating systemic immune responses. However, studies have not examined whether Giardia infections modulate systemic immune responses to microbial pathogens at distant tissue sites. Currently, a few studies have demonstrated that Giardia infections can be observed in association with blood-borne parasites, such as Plasmodium sp. [191] and Leishmania sp. [192]. In addition, individuals with immune deficiencies, such as HIV/AIDS, may be more susceptible to Giardia infection [193-195]. However, our understanding of how immunomodulatory mechanisms employed by Giardia may alter infection dynamics is poor, and research is this field is sorely needed.

\section{Summary}

Our understanding of Giardia infections is continually improving, and it is now apparent that parasites possess multiple mechanisms capable of modulating host intestinal inflammatory responses, yet much remains to be uncovered (Figure 3). Moreover, human studies indicate that infections can be commonly found in association with other pro-inflammatory GI pathogens, especially in developing countries, and, in certain instances, infections have been shown to protect against the development of diarrheal disease. It remains to be causally demonstrated whether the parasites' immunomodulatory mechanisms are responsible for the attenuating diarrheal disease within their host. Therefore, future studies need to assess the immunomodulatory mechanisms of Giardia infections in the context of the attenuation of diarrheal disease. Interestingly, experimental evidence to date suggests that certain immunomodulatory capabilities of the parasite are associated with different Giardia assemblages, and future research needs to assess whether similar effects are observed in humans. These observations may lend further support to the discussion on Giardia assemblage A and B speciation. Finally, it remains to be seen whether Giardia infections are capable of modulating systemic immune responses or immune responses at distant organ tissues. As the highest incidence rates of Giardia infections geographically overlap with various other microbial pathogens, future research needs to consider whether Giardia infections modulate host immune responses to pathogens at sites distant from the GI tract. 


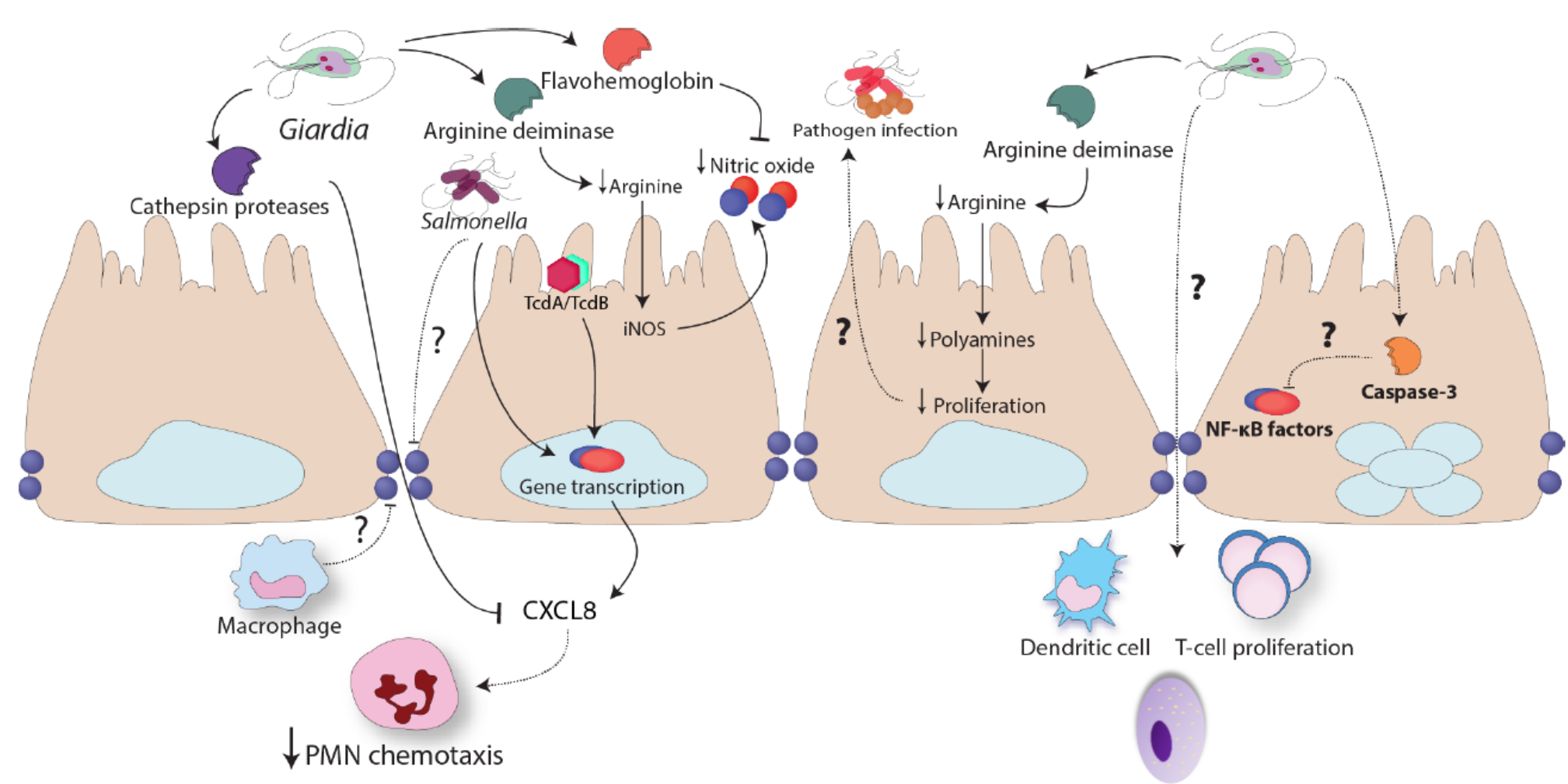

Mast cell hyperplasia

Figure 3. Immunomodulation by Giardia sp. Giardia infections have been shown to attenuate granulocyte infiltration in vivo following intra-rectal instillation of Clostridium difficile toxin A and B (TcdA/TcdB). Giardia trophozoites release cathepsin cysteine proteases that attenuate PMN chemotaxis; it remains unknown how these proteases cross the intestinal epithelial barrier. Arginine deiminase (ADI) released by the parasite consumes L-arginine and this results in attenuated nitric oxide (NO) production. Furthermore, flavohemoglobins released by the parasite decrease the levels of NO. Giardia arginine deiminase also decreases intestinal epithelial proliferation, and this may affect the ability of other pathogens to colonize the intestinal tract. Similarly, during trophozoite-induced intestinal epithelial apoptosis, the activation of caspase proteins may cleave pro-inflammatory transcription factors. Multiple reports have shown that Giardia trophozoites modulate dendritic cell and helper $\mathrm{T}$ cell function, and cause mast cell hyperplasia. Additional research is required to characterize the mechanisms and consequences of these observations. 


\section{Acknowledgments}

James A. Cotton is funded by an $\mathrm{MD} / \mathrm{PhD}$ scholarship from Alberta Innovates and Health Solutions. Parts of the research discussed in this review were funded by grants from the Natural Sciences and Engineering Research Council of Canada, and Crohn's and Colitis Canada.

\section{Author Contributions}

James A. Cotton, Christina B. Amat and Andre G. Buret wrote the manuscript. James A. Cotton and Andre G. Buret designed the phylogenetic trees and analyzed the data.

\section{Conflicts of Interest}

The authors declare no conflict of interest.

\section{References}

1. Lane, S.; Lloyd, D. Current trends in research into the waterborne parasite Giardia. Crit. Rev. Microbiol. 2002, 28, 123-147.

2. Liu, J.; Kabir, F.; Manneh, J.; Lertsethtakarn, P.; Begum, S.; Gratz, J.; Becker, S.M.; Operario, D.J.; Taniuchi, M.; Janaki, L.; et al. Development and assessment of molecular diagnostic tests for 15 enteropathogens causing childhood diarrhoea: A multicentre study. Lancet Infect. Dis. 2014, 14, 716-724.

3. Mejia, R.; Vicuna, Y.; Broncano, N.; Sandoval, C.; Vaca, M.; Chico, M.; Cooper, P.J.; Nutman, T.B. A novel, multi-parallel, real-time polymerase chain reaction approach for eight gastrointestinal parasites provides improved diagnostic capabilities to resource-limited at-risk populations. Am. J. Trop. Med. Hyg. 2013, 88, 1041-1047.

4. Nash, T.E.; Herrington, D.A.; Losonsky, G.A.; Levine, M.M. Experimental human infections with Giardia lamblia. J. Infect. Dis. 1987, 156, 974-984.

5. Savioli, L.; Smith, H.; Thompson, A. Giardia and Cryptosporidium join the "neglected diseases initiative". Trends Parasitol. 2006, 22, 203-208.

6. Escobedo, A.A.; Arencibia, R.; Vega, R.L.; Rodriguez-Morales, A.J.; Almirall, P.; Alfonso, M. A bibliometric study of international scientific productivity in giardiasis covering the period 1971-2010. J. Infect. Dev. Ctries 2015, 9, 76-86.

7. Cotton, J.A.; Beatty, J.K.; Buret, A.G. Host parasite interactions and pathophysiology in Giardia infections. Int. J. Parasitol. 2011, 41, 925-933.

8. Halliez, M.C.; Buret, A.G. Extra-intestinal and long term consequences of Giardia duodenalis infections. World J. Gastroenterol. 2013, 19, 8974-8985.

9. Wensaas, K.A.; Langeland, N.; Hanevik, K.; Morch, K.; Eide, G.E.; Rortveit, G. Irritable bowel syndrome and chronic fatigue 3 years after acute giardiasis: Historic cohort study. Gut 2012, 61, 214-219.

10. Robertson, L.J.; Hanevik, K.; Escobedo, A.A.; Morch, K.; Langeland, N. Giardiasis-Why do the symptoms sometimes never stop? Trends Parasitol. 2010, 26, 75-82. 
11. Istre, G.R.; Dunlop, T.S.; Gaspard, G.B.; Hopkins, R.S. Waterborne giardiasis at a mountain resort: Evidence for acquired immunity. Am. J. Public Health 1984, 74, 602-604.

12. Monis, P.T.; Caccio, S.M.; Thompson, R.C. Variation in Giardia: Towards a taxonomic revision of the genus. Trends Parasitol. 2009, 25, 93-100.

13. Lasek-Nesselquist, E.; Welch, D.M.; Sogin, M.L. The identification of a new Giardia duodenalis assemblage in marine vertebrates and a preliminary analysis of g. Duodenalis population biology in marine systems. Int. J. Parasitol. 2010, 40, 1063-1074.

14. Haque, R.; Roy, S.; Kabir, M.; Stroup, S.E.; Mondal, D.; Houpt, E.R. Giardia assemblage a infection and diarrhea in bangladesh. J. Infect. Dis. 2005, 192, 2171-2173.

15. Pestechian, N.; Rasekh, H.; Rostami-Nejad, M.; Yousofi, H.A.; Hosseini-Safa, A. Molecular identification of Giardia lamblia; is there any correlation between diarrhea and genotyping in iranian population? Gastroenterol. Hepatol. Bed Bench 2014, 7, 168-172.

16. ElBakri, A.; Samie, A.; Bessong, P.; Potgieter, N.; Odeh, R.A. Detection and molecular characterisation of Giardia lamblia genotypes in sharjah, united arab emirates. Trans R. Soc. Trop. Med. Hyg. 2014, 108, 466-473.

17. Puebla, L.J.; Nunez, F.A.; Fernandez, Y.A.; Fraga, J.; Rivero, L.R.; Millan, I.A.; Valdes, L.A.; Silva, I.M. Correlation of Giardia duodenalis assemblages with clinical and epidemiological data in cuban children. Infect. Genet. Evol. 2014, 23, 7-12.

18. Minetti, C.; Lamden, K.; Durband, C.; Cheesbrough, J.; Platt, K.; Charlett, A.; O’Brien, S.J.; Fox, A.; Wastling, J.M. Case-control study of risk factors for sporadic giardiasis and parasite assemblages in north west england. J. Clin. Microbiol. 2015.

19. Solaymani-Mohammadi, S.; Singer, S.M. Host immunity and pathogen strain contribute to intestinal disaccharidase impairment following gut infection. J. Immunol. 2011, 187, 3769-3775.

20. Franzen, O.; Jerlstrom-Hultqvist, J.; Castro, E.; Sherwood, E.; Ankarklev, J.; Reiner, D.S.; Palm, D.; Andersson, J.O.; Andersson, B.; Svard, S.G. Draft genome sequencing of Giardia intestinalis assemblage B isolate GS: Is human giardiasis caused by two different species? PLoS Pathog. 2009, doi:10.1371/journal.ppat.1000560.

21. Adam, R.D.; Dahlstrom, E.W.; Martens, C.A.; Bruno, D.P.; Barbian, K.D.; Ricklefs, S.M.; Hernandez, M.M.; Narla, N.P.; Patel, R.B.; Porcella, S.F.; et al. Genome sequencing of Giardia lamblia genotypes $\mathrm{A} 2$ and $\mathrm{B}$ isolates (DH and GS) and comparative analysis with the genomes of genotypes A1 and E (WB and Pig). Genome Biol. Evol. 2013, 5, 2498-2511.

22. Jerlstrom-Hultqvist, J.; Ankarklev, J.; Svard, S.G. Is human giardiasis caused by two different Giardia species? Gut Microbes 2010, 1, 379-382.

23. Bartelt, L.A.; Sartor, R.B. Advances in understanding Giardia: Determinants and mechanisms of chronic sequelae. F1000Prime Rep. 2015, doi:10.12703/P7-62.

24. Klotz, C.; Aebischer, T. The immunological enigma of human giardiasis. Curr. Trop. Med. Rep. 2015, 2, 1-9.

25. Solaymani-Mohammadi, S.; Singer, S.M. Giardia duodenalis: The double-edged sword of immune responses in giardiasis. Exp. Parasitol. 2010, 126, 292-297.

26. Buret, A.; Amat, C.; Manko, A.; Beatty, J.; Halliez, M.M.; Bhargava, A.; Motta, J.-P.; Cotton, J. Giardia duodenalis: New research developments in pathophysiology, pathogenesis, and virulence factors. Curr. Trop. Med. Rep. 2015, 2, 110-118. 
27. Maizels, R.M. Parasite immunomodulation and polymorphisms of the immune system. J. Biol. 2009, 8, 62 .

28. McSorley, H.J.; Maizels, R.M. Helminth infections and host immune regulation. Clin. Microbiol. Rev. 2012, 25, 585-608.

29. Turner, J.R. Intestinal mucosal barrier function in health and disease. Nat. Rev. Immunol. 2009, 9, 799-809.

30. McGuckin, M.A.; Linden, S.K.; Sutton, P.; Florin, T.H. Mucin dynamics and enteric pathogens. Nat. Rev. Microbiol. 2011, 9, 265-278.

31. Hollander, D.; Vadheim, C.M.; Brettholz, E.; Petersen, G.M.; Delahunty, T.; Rotter, J.I. Increased intestinal permeability in patients with crohn's disease and their relatives. A possible etiologic factor. Ann. Intern. Med. 1986, 105, 883-885.

32. Buhner, S.; Buning, C.; Genschel, J.; Kling, K.; Herrmann, D.; Dignass, A.; Kuechler, I.; Krueger, S.; Schmidt, H.H.; Lochs, H. Genetic basis for increased intestinal permeability in families with crohn's disease: Role of card15 3020insc mutation? Gut 2006, 55, 342-347.

33. O'Hara, J.R.; Buret, A.G. Mechanisms of intestinal tight junctional disruption during infection. Front. Biosci. 2008, 13, 7008-7021.

34. Berkes, J.; Viswanathan, V.K.; Savkovic, S.D.; Hecht, G. Intestinal epithelial responses to enteric pathogens: Effects on the tight junction barrier, ion transport, and inflammation. Gut 2003, 52, 439-451.

35. Chin, A.C.; Teoh, D.A.; Scott, K.G.; Meddings, J.B.; Macnaughton, W.K.; Buret, A.G. Strain-dependent induction of enterocyte apoptosis by Giardia lamblia disrupts epithelial barrier function in a caspase-3-dependent manner. Infect. Immun. 2002, 70, 3673-3680.

36. Scott, K.G.; Meddings, J.B.; Kirk, D.R.; Lees-Miller, S.P.; Buret, A.G. Intestinal infection with Giardia spp. Reduces epithelial barrier function in a myosin light chain kinase-dependent fashion. Gastroenterology 2002, 123, 1179-1190.

37. Troeger, H.; Epple, H.J.; Schneider, T.; Wahnschaffe, U.; Ullrich, R.; Burchard, G.D.; Jelinek, T.; Zeitz, M.; Fromm, M.; Schulzke, J.D. Effect of chronic Giardia lamblia infection on epithelial transport and barrier function in human duodenum. Gut 2007, 56, 328-335.

38. Teoh, D.A.; Kamieniecki, D.; Pang, G.; Buret, A.G. Giardia lamblia rearranges f-actin and alpha-actinin in human colonic and duodenal monolayers and reduces transepithelial electrical resistance. J. Parasitol. 2000, 86, 800-806.

39. Panaro, M.A.; Cianciulli, A.; Mitolo, V.; Mitolo, C.I.; Acquafredda, A.; Brandonisio, O.; Cavallo, P. Caspase-dependent apoptosis of the het- 8 epithelial cell line induced by the parasite Giardia intestinalis. FEMS Immunol. Med. Microbiol. 2007, 51, 302-309.

40. Reynoso-Robles, R.; Ponce-Macotela, M.; Rosas-Lopez, L.E.; Ramos-Morales, A.; Martinez-Gordillo, M.N.; Gonzalez-Maciel, A. The invasive potential of Giardia intestinalis in an in vivo model. Sci. Rep. 2015, doi:10.1038/srep15168.

41. Oberhuber, G.; Kastner, N.; Stolte, M. Giardiasis: A histologic analysis of 567 cases. Scand. J. Gastroenterol. 1997, 32, 48-51.

42. Campbell, D.I.; McPhail, G.; Lunn, P.G.; Elia, M.; Jeffries, D.J. Intestinal inflammation measured by fecal neopterin in gambian children with enteropathy: Association with growth failure, Giardia lamblia, and intestinal permeability. J. Pediatr. Gastroenterol. Nutr. 2004, 39, 153-157. 
43. Craven, M.; Egan, C.E.; Dowd, S.E.; McDonough, S.P.; Dogan, B.; Denkers, E.Y.; Bowman, D.; Scherl, E.J.; Simpson, K.W. Inflammation drives dysbiosis and bacterial invasion in murine models of ileal crohn's disease. PLoS ONE 2012, doi:10.1371/journal.pone.0041594.

44. Scott, K.G.; Yu, L.C.; Buret, A.G. Role of cd8+ and cd4+ t lymphocytes in jejunal mucosal injury during murine giardiasis. Infect. Immun. 2004, 72, 3536-3542.

45. Hardin, J.A.; Buret, A.G.; Olson, M.E.; Kimm, M.H.; Gall, D.G. Mast cell hyperplasia and increased macromolecular uptake in an animal model of giardiasis. J. Parasitol. 1997, 83, 908-912.

46. Dreesen, L.; Rinaldi, M.; Chiers, K.; Li, R.; Geurden, T.; van den Broeck, W.; Goddeeris, B.; Vercruysse, J.; Claerebout, E.; Geldhof, P. Microarray analysis of the intestinal host response in Giardia duodenalis assemblage $\mathrm{E}$ infected calves. PLoS ONE 2012, doi:10.1371/journal.pone.0040985.

47. Jung, H.C.; Eckmann, L.; Yang, S.K.; Panja, A.; Fierer, J.; Morzycka-Wroblewska, E.; Kagnoff, M.F. A distinct array of proinflammatory cytokines is expressed in human colon epithelial cells in response to bacterial invasion. J. Clin. Investig. 1995, 95, 55-65.

48. Eckmann, L.; Laurent, F.; Langford, T.D.; Hetsko, M.L.; Smith, J.R.; Kagnoff, M.F.; Gillin, F.D. Nitric oxide production by human intestinal epithelial cells and competition for arginine as potential determinants of host defense against the lumen-dwelling pathogen Giardia lamblia. J. Immunol. 2000, 164, 1478-1487.

49. Roxstrom-Lindquist, K.; Ringqvist, E.; Palm, D.; Svard, S. Giardia lamblia-induced changes in gene expression in differentiated caco-2 human intestinal epithelial cells. Infect. Immun. 2005, 73, 8204-8208.

50. Veenemans, J.; Mank, T.; Ottenhof, M.; Baidjoe, A.; Mbugi, E.V.; Demir, A.Y.; Wielders, J.P.; Savelkoul, H.F.; Verhoef, H. Protection against diarrhea associated with Giardia intestinalis is lost with multi-nutrient supplementation: A study in tanzanian children. PLoS Negl. Trop. Dis. 2011, 5, doi: 10.1371/journal.pntd.0001158.

51. Hanevik, K.; Hausken, T.; Morken, M.H.; Strand, E.A.; Morch, K.; Coll, P.; Helgeland, L.; Langeland, N. Persisting symptoms and duodenal inflammation related to Giardia duodenalis infection. J. Infect. 2007, 55, 524-530.

52. Chen, T.L.; Chen, S.; Wu, H.W.; Lee, T.C.; Lu, Y.Z.; Wu, L.L.; Ni, Y.H.; Sun, C.H.; Yu, W.H.; Buret, A.G.; et al. Persistent gut barrier damage and commensal bacterial influx following eradication of Giardia infection in mice. Gut Pathog. 2013, 5, 26.

53. Benere, E.; van Assche, T.; van Ginneken, C.; Peulen, O.; Cos, P.; Maes, L. Intestinal growth and pathology of Giardia duodenalis assemblage subtype a(i), a(ii), b and e in the gerbil model. Parasitology 2012, 139, 424-433.

54. Lee, H.Y.; Hyung, S.; Lee, N.Y.; Yong, T.S.; Han, S.H.; Park, S.J. Excretory-secretory products of Giardia lamblia induce interleukin-8 production in human colonic cells via activation of $\mathrm{p} 38$, erk1/2, nf-kappab and ap-1. Parasite Immunol. 2012, 34, 183-198.

55. Dos Santos, J.I.; Vituri Cde, L. Some hematimetric findings in human Giardia lamblia infection. Rev. Inst. Med. Trop. Sao Paulo 1996, 38, 91-95. 
56. Koot, B.G.; ten Kate, F.J.; Juffrie, M.; Rosalina, I.; Taminiau, J.J.; Benninga, M.A. Does Giardia lamblia cause villous atrophy in children?: A retrospective cohort study of the histological abnormalities in giardiasis. J. Pediatr. Gastroenterol. Nutr. 2009, 49, 304-308.

57. Aloisio, F.; Filippini, G.; Antenucci, P.; Lepri, E.; Pezzotti, G.; Caccio, S.M.; Pozio, E. Severe weight loss in lambs infected with Giardia duodenalis assemblage b. Vet. Parasitol. 2006, 142, 154-158.

58. Bartelt, L.A.; Roche, J.; Kolling, G.; Bolick, D.; Noronha, F.; Naylor, C.; Hoffman, P.; Warren, C.; Singer, S.; Guerrant, R. Persistent g. Lamblia impairs growth in a murine malnutrition model. J. Clin. Investig. 2013, 123, 2672-2684.

59. Jimenez, J.C.; Fontaine, J.; Grzych, J.M.; Dei-Cas, E.; Capron, M. Systemic and mucosal responses to oral administration of excretory and secretory antigens from Giardia intestinalis. Clin. Diagn Lab. Immunol. 2004, 11, 152-160.

60. Ankarklev, J.; Jerlstrom-Hultqvist, J.; Ringqvist, E.; Troell, K.; Svard, S.G. Behind the smile: Cell biology and disease mechanisms of Giardia species. Nat. Rev. Microbiol. 2010, 8, 413-422.

61. Mahmoudi, M.R.; Kazemi, B.; Mohammadiha, A.; Mirzaei, A.; Karanis, P. Detection of Cryptosporidium and Giardia (oo)cysts by IFA, PCR and LAMP in surface water from Rasht, Iran. Trans. R. Soc. Trop. Med. Hyg. 2013, 107, 511-517.

62. Mohamed, A.S.; Levine, M.; Camp, J.W., Jr.; Lund, E.; Yoder, J.S.; Glickman, L.T.; Moore, G.E. Temporal patterns of human and canine Giardia infection in the united states: 2003-2009. Prev. Vet. Med. 2014, 113, 249-256.

63. Muhsen, K.; Levine, M.M. A systematic review and meta-analysis of the association between Giardia lamblia and endemic pediatric diarrhea in developing countries. Clin. Infect. Dis. 2012, 55 (Suppl. S4), S271-S293.

64. Kotloff, K.L.; Nataro, J.P.; Blackwelder, W.C.; Nasrin, D.; Farag, T.H.; Panchalingam, S.; Wu, Y.; Sow, S.O.; Sur, D.; Breiman, R.F.; et al. Burden and aetiology of diarrhoeal disease in infants and young children in developing countries (the global enteric multicenter study, gems): A prospective, case-control study. Lancet 2013, 382, 209-222.

65. Ankarklev, J.; Hestvik, E.; Lebbad, M.; Lindh, J.; Kaddu-Mulindwa, D.H.; Andersson, J.O.; Tylleskar, T.; Tumwine, J.K.; Svard, S.G. Common coinfections of Giardia intestinalis and helicobacter pylori in non-symptomatic ugandan children. PLoS Negl. Trop. Dis. 2012, doi:10.1371/journal.pntd.0001780.

66. Grazioli, B.; Matera, G.; Laratta, C.; Schipani, G.; Guarnieri, G.; Spiniello, E.; Imeneo, M.; Amorosi, A.; Foca, A.; Luzza, F. Giardia lamblia infection in patients with irritable bowel syndrome and dyspepsia: A prospective study. World J. Gastroenterol. 2006, 12, 1941-1944.

67. Mukherjee, A.K.; Chowdhury, P.; Rajendran, K.; Nozaki, T.; Ganguly, S. Association between Giardia duodenalis and coinfection with other diarrhea-causing pathogens in india. Biomed. Res. Int. 2014, doi:10.1155/2014/786480.

68. Bilenko, N.; Levy, A.; Dagan, R.; Deckelbaum, R.J.; El-On, Y.; Fraser, D. Does co-infection with Giardia lamblia modulate the clinical characteristics of enteric infections in young children? Eur. J. Epidemiol. 2004, 19, 877-883. 
69. Hagel, I.; Cabrera, M.; Puccio, F.; Santaella, C.; Buvat, E.; Infante, B.; Zabala, M.; Cordero, R.; Di Prisco, M.C. Co-infection with ascaris lumbricoides modulates protective immune responses against Giardia duodenalis in school venezuelan rural children. Acta Trop. 2011, 117, 189-195.

70. Wang, L.; Xiao, L.; Duan, L.; Ye, J.; Guo, Y.; Guo, M.; Liu, L.; Feng, Y. Concurrent infections of Giardia duodenalis, enterocytozoon bieneusi, and clostridium difficile in children during a cryptosporidiosis outbreak in a pediatric hospital in china. PLoS Negl. Trop. Dis. 2013, doi:10.1371/journal.pntd.0002437.

71. Oberhelman, R.A.; Flores-Abuxapqui, J.; Suarez-Hoil, G.; Puc-Franco, M.; Heredia-Navarrete, M.; Vivas-Rosel, M.; Mera, R.; Gutierrez-Cogco, L. Asymptomatic salmonellosis among children in day-care centers in merida, yucatan, mexico. Pediatr. Infect. Dis. J. 2001, 20, 792-797.

72. Muhsen, K.; Cohen, D.; Levine, M.M. Can Giardia lamblia infection lower the risk of acute diarrhea among preschool children? J. Trop. Pediatr. 2014, 60, 99-103.

73. Bhavnani, D.; Goldstick, J.E.; Cevallos, W.; Trueba, G.; Eisenberg, J.N. Synergistic effects between rotavirus and coinfecting pathogens on diarrheal disease: Evidence from a community-based study in northwestern ecuador. Am. J. Epidemiol. 2012, 176, 387-395.

74. Von Allmen, N.; Christen, S.; Forster, U.; Gottstein, B.; Welle, M.; Muller, N. Acute trichinellosis increases susceptibility to Giardia lamblia infection in the mouse model. Parasitology 2006, 133, 139-149.

75. Elliott, E.; Li, Z.; Bell, C.; Stiel, D.; Buret, A.; Wallace, J.; Brzuszczak, I.; O’Loughlin, E. Modulation of host response to escherichia coli o157:H7 infection by anti-cd18 antibody in rabbits. Gastroenterology 1994, 106, 1554-1561.

76. Johansson, M.E.; Phillipson, M.; Petersson, J.; Velcich, A.; Holm, L.; Hansson, G.C. The inner of the two muc2 mucin-dependent mucus layers in colon is devoid of bacteria. Proc. Natl. Acad. Sci. USA 2008, 105, 15064-15069.

77. Johansson, M.E.; Larsson, J.M.; Hansson, G.C. The two mucus layers of colon are organized by the muc2 mucin, whereas the outer layer is a legislator of host-microbial interactions. Proc. Natl. Acad. Sci. USA 2011, 108, 4659-4665.

78. Gum, J.R., Jr.; Hicks, J.W.; Toribara, N.W.; Siddiki, B.; Kim, Y.S. Molecular cloning of human intestinal mucin (muc2) cdna. Identification of the amino terminus and overall sequence similarity to prepro-von willebrand factor. J. Biol. Chem. 1994, 269, 2440-2446.

79. Tanaka, S.; Mizuno, M.; Maga, T.; Yoshinaga, F.; Tomoda, J.; Nasu, J.; Okada, H.; Yokota, K.; Oguma, K.; Shiratori, Y.; et al. H. Pylori decreases gastric mucin synthesis via inhibition of galactosyltransferase. Hepatogastroenterology 2003, 50, 1739-1742.

80. Tse, S.K.; Chadee, K. Biochemical characterization of rat colonic mucins secreted in response to entamoeba histolytica. Infect. Immun. 1992, 60, 1603-1612.

81. Lidell, M.E.; Moncada, D.M.; Chadee, K.; Hansson, G.C. Entamoeba histolytica cysteine proteases cleave the muc2 mucin in its c-terminal domain and dissolve the protective colonic mucus gel. Proc. Natl. Acad. Sci. USA 2006, 103, 9298-9303.

82. Hasnain, S.Z.; McGuckin, M.A.; Grencis, R.K.; Thornton, D.J. Serine protease(s) secreted by the nematode trichuris muris degrade the mucus barrier. PLoS Negl. Trop. Dis. 2012, doi:10.1371/journal.pntd.0001856. 
83. Song, K.S.; Lee, W.J.; Chung, K.C.; Koo, J.S.; Yang, E.J.; Choi, J.Y.; Yoon, J.H. Interleukin-1 beta and tumor necrosis factor-alpha induce muc5ac overexpression through a mechanism involving erk/p38 mitogen-activated protein kinases-msk1-creb activation in human airway epithelial cells. J. Biol. Chem. 2003, 278, 23243-23250.

84. Smirnova, M.G.; Guo, L.; Birchall, J.P.; Pearson, J.P. Lps up-regulates mucin and cytokine mrna expression and stimulates mucin and cytokine secretion in goblet cells. Cell. Immunol. 2003, 221, 42-49.

85. McKenzie, G.J.; Bancroft, A.; Grencis, R.K.; McKenzie, A.N. A distinct role for interleukin-13 in th2-cell-mediated immune responses. Curr. Biol. 1998, 8, 339-342.

86. Heazlewood, C.K.; Cook, M.C.; Eri, R.; Price, G.R.; Tauro, S.B.; Taupin, D.; Thornton, D.J.; Png, C.W.; Crockford, T.L.; Cornall, R.J.; et al. Aberrant mucin assembly in mice causes endoplasmic reticulum stress and spontaneous inflammation resembling ulcerative colitis. PLoS Med. 2008, doi:10.1371/journal.pmed.0050054.

87. Bergstrom, K.S.; Kissoon-Singh, V.; Gibson, D.L.; Ma, C.; Montero, M.; Sham, H.P.; Ryz, N.; Huang, T.; Velcich, A.; Finlay, B.B.; et al. Muc2 protects against lethal infectious colitis by disassociating pathogenic and commensal bacteria from the colonic mucosa. PLoS Pathog. 2010, doi:10.1371/journal.ppat.1000902.

88. Kissoon-Singh, V.; Moreau, F.; Trusevych, E.; Chadee, K. Entamoeba histolytica exacerbates epithelial tight junction permeability and proinflammatory responses in Muc2 $2^{(-/)}$mice. Am. J. Pathol. 2013, 182, 852-865.

89. Hasnain, S.Z.; Wang, H.; Ghia, J.E.; Haq, N.; Deng, Y.; Velcich, A.; Grencis, R.K.; Thornton, D.J.; Khan, W.I. Mucin gene deficiency in mice impairs host resistance to an enteric parasitic infection. Gastroenterology 2010, 138, 1763-1771.

90. Larsson, J.M.; Karlsson, H.; Crespo, J.G.; Johansson, M.E.; Eklund, L.; Sjovall, H.; Hansson, G.C. Altered o-glycosylation profile of muc 2 mucin occurs in active ulcerative colitis and is associated with increased inflammation. Inflamm. Bowel Dis. 2011, 17, 2299-2307.

91. Tytgat, K.M.; van der Wal, J.W.; Einerhand, A.W.; Buller, H.A.; Dekker, J. Quantitative analysis of muc2 synthesis in ulcerative colitis. Biochem. Biophys. Res. Commun. 1996, 224, 397-405.

92. Van Klinken, B.J.; van der Wal, J.W.; Einerhand, A.W.; Buller, H.A.; Dekker, J. Sulphation and secretion of the predominant secretory human colonic mucin muc2 in ulcerative colitis. Gut 1999, 44, 387-393.

93. Amulic, B.; Cazalet, C.; Hayes, G.L.; Metzler, K.D.; Zychlinsky, A. Neutrophil function: From mechanisms to disease. Annu. Rev. Immunol. 2012, 30, 459-489.

94. Van Haastert, P.J.; Devreotes, P.N. Chemotaxis: Signalling the way forward. Nat. Rev. Mol. Cell. Biol. 2004, 5, 626-634.

95. Thelen, M. Dancing to the tune of chemokines. Nat. Immunol. 2001, 2, 129-134.

96. Chin, A.C.; Parkos, C.A. Pathobiology of neutrophil transepithelial migration: Implications in mediating epithelial injury. Annu. Rev. Pathol. 2007, 2, 111-143.

97. Madara, J.L.; Patapoff, T.W.; Gillece-Castro, B.; Colgan, S.P.; Parkos, C.A.; Delp, C.; Mrsny, R.J. 5'-adenosine monophosphate is the neutrophil-derived paracrine factor that elicits chloride secretion from t84 intestinal epithelial cell monolayers. J. Clin. Investig. 1993, 91, 2320-2325. 
98. Madara, J.L.; Parkos, C.; Colgan, S.; MacLeod, R.J.; Nash, S.; Matthews, J.; Delp, C.; Lencer, W. Cl- secretion in a model intestinal epithelium induced by a neutrophil-derived secretagogue. J. Clin. Investig. 1992, 89, 1938-1944.

99. Weissmuller, T.; Campbell, E.L.; Rosenberger, P.; Scully, M.; Beck, P.L.; Furuta, G.T.; Colgan, S.P. Pmns facilitate translocation of platelets across human and mouse epithelium and together alter fluid homeostasis via epithelial cell-expressed ecto-ntpdases. J. Clin. Investig. 2008, 118, 3682-3692.

100. Cotton, J.A.; Motta, J.P.; Schenck, L.P.; Hirota, S.A.; Beck, P.L.; Buret, A.G. Giardia duodenalis infection reduces granulocyte infiltration in an in vivo model of bacterial toxin-induced colitis and attenuates inflammation in human intestinal tissue. PLoS ONE 2014, doi:10.1371/journal.pone.0109087.

101. Cotton, J.A.; Bhargava, A.; Ferraz, J.G.; Yates, R.M.; Beck, P.L.; Buret, A.G. Giardia duodenalis cathepsin $\mathrm{b}$ proteases degrade intestinal epithelial interleukin- 8 and attenuate interleukin- 8 -induced neutrophil chemotaxis. Infect. Immun. 2014, 82, 2772-2787.

102. Bhargava, A.; Cotton, J.A.; Dixon, B.R.; Gedamu, L.; Yates, R.M.; Buret, A.G. Giardia duodenalis surface cysteine proteases induce cleavage of the intestinal epithelial cytoskeletal protein villin via myosin light chain kinase. PLoS ONE 2015, doi:10.1371/journal.pone.0136102.

103. Turk, V.; Stoka, V.; Vasiljeva, O.; Renko, M.; Sun, T.; Turk, B.; Turk, D. Cysteine cathepsins: From structure, function and regulation to new frontiers. Biochim. Biophys. Acta 2012, 1824, 68-88.

104. Aurrecoechea, C.; Brestelli, J.; Brunk, B.P.; Carlton, J.M.; Dommer, J.; Fischer, S.; Gajria, B.; Gao, X.; Gingle, A.; Grant, G.; et al. Giardiadb and trichdb: Integrated genomic resources for the eukaryotic protist pathogens Giardia lamblia and trichomonas vaginalis. Nucleic Acids Res. 2009, 37, D526-D530.

105. Sajid, M.; McKerrow, J.H. Cysteine proteases of parasitic organisms. Mol. Biochem. Parasitol. 2002, 120, 1-21.

106. DuBois, K.N.; Abodeely, M.; Sakanari, J.; Craik, C.S.; Lee, M.; McKerrow, J.H.; Sajid, M. Identification of the major cysteine protease of Giardia and its role in encystation. J. Biol. Chem. 2008, 283, 18024-18031.

107. Dou, Z.; Coppens, I.; Carruthers, V.B. Non-canonical maturation of two papain-family proteases in toxoplasma gondii. J. Biol. Chem. 2013, 288, 3523-3534.

108. Sievers, F.; Wilm, A.; Dineen, D.; Gibson, T.J.; Karplus, K.; Li, W.; Lopez, R.; McWilliam, H.; Remmert, M.; Söding, J.; et al. Fast, scalable generation of high-quality protein multiple sequence alignments using clustal omega. Mol. Syst. Biol. 2011, 7, 539.

109. Wampfler, P.B.; Faso, C.; Hehl, A.B. The cre/loxp system in Giardia lamblia: Genetic manipulations in a binucleate tetraploid protozoan. Int. J. Parasitol. 2014, 44, 497-506.

110. McKerrow, J.H.; Caffrey, C.; Kelly, B.; Loke, P.; Sajid, M. Proteases in parasitic diseases. Annu. Rev. Pathol. 2006, 1, 497-536.

111. Que, X.; Kim, S.H.; Sajid, M.; Eckmann, L.; Dinarello, C.A.; McKerrow, J.H.; Reed, S.L. A surface amebic cysteine proteinase inactivates interleukin-18. Infect. Immun. 2003, 71, 1274-1280. 
112. Reed, S.L.; Ember, J.A.; Herdman, D.S.; DiScipio, R.G.; Hugli, T.E.; Gigli, I. The extracellular neutral cysteine proteinase of entamoeba histolytica degrades anaphylatoxins c3a and c5a. J. Immunol. 1995, 155, 266-274.

113. Mumy, K.L.; McCormick, B.A. Events at the host-microbial interface of the gastrointestinal tract. Ii. Role of the intestinal epithelium in pathogen-induced inflammation. Am. J. Physiol. Gastrointest. Liver Physiol. 2005, 288, G854-859.

114. McCormick, B.A.; Colgan, S.P.; Delp-Archer, C.; Miller, S.I.; Madara, J.L. Salmonella typhimurium attachment to human intestinal epithelial monolayers: Transcellular signalling to subepithelial neutrophils. J. Cell Biol. 1993, 123, 895-907.

115. McCormick, B.A.; Miller, S.I.; Carnes, D.; Madara, J.L. Transepithelial signaling to neutrophils by salmonellae: A novel virulence mechanism for gastroenteritis. Infect. Immun. 1995, 63, 2302-2309.

116. Fisher, B.S.; Estrano, C.E.; Cole, J.A. Modeling long-term host cell-Giardia lamblia interactions in an in vitro co-culture system. PLOS ONE 2013, doi:10.1371/journal.pone.0081104.

117. Zareie, M.; McKay, D.M.; Kovarik, G.G.; Perdue, M.H. Monocyte/macrophages evoke epithelial dysfunction: Indirect role of tumor necrosis factor-alpha. Am. J. Physiol. 1998, 275, C932-C939.

118. Kostman, R. Infantile genetic agranulocytosis. A review with presentation of ten new cases. Acta Paediatr. Scand. 1975, 64, 362-368.

119. Zeidler, C.; Germeshausen, M.; Klein, C.; Welte, K. Clinical implications of ela2-, hax1-, and g-csf-receptor (csf3r) mutations in severe congenital neutropenia. Br. J. Haematol. 2009, 144, 459-467.

120. Kuijpers, T.; Lutter, R. Inflammation and repeated infections in cgd: Two sides of a coin. Cell. Mol. Life Sci. 2012, 69, 7-15.

121. Jarchum, I.; Liu, M.; Shi, C.; Equinda, M.; Pamer, E.G. Critical role for myd88-mediated neutrophil recruitment during clostridium difficile colitis. Infect. Immun. 2012, 80, 2989-2996.

122. Hasegawa, M.; Yamazaki, T.; Kamada, N.; Tawaratsumida, K.; Kim, Y.G.; Nunez, G.; Inohara, N. Nucleotide-binding oligomerization domain 1 mediates recognition of clostridium difficile and induces neutrophil recruitment and protection against the pathogen. J. Immunol. 2011, 186, 4872-4880.

123. Spehlmann, M.E.; Dann, S.M.; Hruz, P.; Hanson, E.; McCole, D.F.; Eckmann, L. Cxcr2-dependent mucosal neutrophil influx protects against colitis-associated diarrhea caused by an attaching/effacing lesion-forming bacterial pathogen. J. Immunol. 2009, 183, 3332-3343.

124. Stecher, B.; Hardt, W.D. The role of microbiota in infectious disease. Trends Microbiol. 2008, 16, 107-114.

125. Stecher, B.; Robbiani, R.; Walker, A.W.; Westendorf, A.M.; Barthel, M.; Kremer, M.; Chaffron, S.; Macpherson, A.J.; Buer, J.; Parkhill, J.; et al. Salmonella enterica serovar Typhimurium exploits inflammation to compete with the intestinal microbiota. PLoS Biol. 2007, 5, 2177-2189.

126. Liu, J.Z.; Jellbauer, S.; Poe, A.J.; Ton, V.; Pesciaroli, M.; Kehl-Fie, T.E.; Restrepo, N.A.; Hosking, M.P.; Edwards, R.A.; Battistoni, A.; et al. Zinc sequestration by the neutrophil protein calprotectin enhances Salmonella growth in the inflamed gut. Cell Host Microbe 2012, 11, 227-239. 
127. Winter, S.E.; Thiennimitr, P.; Winter, M.G.; Butler, B.P.; Huseby, D.L.; Crawford, R.W.; Russell, J.M.; Bevins, C.L.; Adams, L.G.; Tsolis, R.M.; et al. Gut inflammation provides a respiratory electron acceptor for Salmonella. Nature 2010, 467, 426-429.

128. Thiennimitr, P.; Winter, S.E.; Winter, M.G.; Xavier, M.N.; Tolstikov, V.; Huseby, D.L.; Sterzenbach, T.; Tsolis, R.M.; Roth, J.R.; Baumler, A.J. Intestinal inflammation allows Salmonella to use ethanolamine to compete with the microbiota. Proc. Natl. Acad. Sci. USA 2011, 108, $17480-17485$.

129. Sun, X.; Liu, B.; Sartor, R.B.; Jobin, C. Phosphatidylinositol 3-kinase-gamma signaling promotes campylobacter jejuni-induced colitis through neutrophil recruitment in mice. J. Immunol. 2013, 190, 357-365.

130. Khan, M.A.; Ma, C.; Knodler, L.A.; Valdez, Y.; Rosenberger, C.M.; Deng, W.; Finlay, B.B.; Vallance, B.A. Toll-like receptor 4 contributes to colitis development but not to host defense during citrobacter rodentium infection in mice. Infect. Immun. 2006, 74, 2522-2536.

131. Kuhl, A.A.; Kakirman, H.; Janotta, M.; Dreher, S.; Cremer, P.; Pawlowski, N.N.; Loddenkemper, C.; Heimesaat, M.M.; Grollich, K.; Zeitz, M.; et al. Aggravation of different types of experimental colitis by depletion or adhesion blockade of neutrophils. Gastroenterology 2007, 133, 1882-1892.

132. Campbell, E.L.; Bruyninckx, W.J.; Kelly, C.J.; Glover, L.E.; McNamee, E.N.; Bowers, B.E.; Bayless, A.J.; Scully, M.; Saeedi, B.J.; Golden-Mason, L.; et al. Transmigrating neutrophils shape the mucosal microenvironment through localized oxygen depletion to influence resolution of inflammation. Immunity 2014, 40, 66-77.

133. Zindl, C.L.; Lai, J.F.; Lee, Y.K.; Maynard, C.L.; Harbour, S.N.; Ouyang, W.; Chaplin, D.D.; Weaver, C.T. Il-22-producing neutrophils contribute to antimicrobial defense and restitution of colonic epithelial integrity during colitis. Proc. Natl. Acad. Sci. USA 2013, 110, 12768-12773.

134. Morris, S.M., Jr. Arginine: Beyond protein. Am. J. Clin. Nutr. 2006, 83, 508S-512S.

135. Das, P.; Lahiri, A.; Lahiri, A.; Chakravortty, D. Modulation of the arginase pathway in the context of microbial pathogenesis: A metabolic enzyme moonlighting as an immune modulator. PLoS Pathog. 2010, doi:10.1371/journal.ppat.1000899.

136. Schofield, P.J.; Costello, M.; Edwards, M.R.; O’Sullivan, W.J. The arginine dihydrolase pathway is present in Giardia intestinalis. Int. J. Parasitol. 1990, 20, 697-699.

137. Stadelmann, B.; Merino, M.C.; Persson, L.; Svard, S.G. Arginine consumption by the intestinal parasite Giardia intestinalis reduces proliferation of intestinal epithelial cells. PLOS ONE 2012, doi:10.1371/journal.pone.0045325.

138. Tako, E.A.; Hassimi, M.F.; Li, E.; Singer, S.M. Transcriptomic analysis of the host response to Giardia duodenalis infection reveals redundant mechanisms for parasite control. MBio 2013, 4, e00660-e00613.

139. Andersen, Y.S.; Gillin, F.D.; Eckmann, L. Adaptive immunity-dependent intestinal hypermotility contributes to host defense against Giardia spp. Infect. Immun. 2006, 74, 2473-2476.

140. Li, E.; Zhou, P.; Singer, S.M. Neuronal nitric oxide synthase is necessary for elimination of Giardia lamblia infections in mice. J. Immunol. 2006, 176, 516-521.

141. Ringqvist, E.; Palm, J.E.; Skarin, H.; Hehl, A.B.; Weiland, M.; Davids, B.J.; Reiner, D.S.; Griffiths, W.J.; Eckmann, L.; Gillin, F.D.; et al. Release of metabolic enzymes by Giardia in response to interaction with intestinal epithelial cells. Mol. Biochem. Parasitol. 2008, 159, 85-91. 
142. Ringqvist, E.; Avesson, L.; Soderbom, F.; Svard, S.G. Transcriptional changes in Giardia during host-parasite interactions. Int. J. Parasitol. 2011, 41, 277-285.

143. Lundberg, J.O.; Weitzberg, E.; Gladwin, M.T. The nitrate-nitrite-nitric oxide pathway in physiology and therapeutics. Nat. Rev. Drug Discov. 2008, 7, 156-167.

144. Salzman, A.; Denenberg, A.G.; Ueta, I.; O’Connor, M.; Linn, S.C.; Szabo, C. Induction and activity of nitric oxide synthase in cultured human intestinal epithelial monolayers. Am. J. Physiol. 1996, 270, G565-G573.

145. Witthoft, T.; Eckmann, L.; Kim, J.M.; Kagnoff, M.F. Enteroinvasive bacteria directly activate expression of inos and no production in human colon epithelial cells. Am. J. Physiol. 1998, 275, G564-G571.

146. Clark, I.A.; Rockett, K.A. Nitric oxide and parasitic disease. Adv. Parasitol. 1996, 37, 1-56.

147. Fang, F.C. Perspectives series: Host/pathogen interactions. Mechanisms of nitric oxide-related antimicrobial activity. J. Clin. Investig. 1997, 99, 2818-2825.

148. James, S.L. Role of nitric oxide in parasitic infections. Microbiol. Rev. 1995, 59, 533-547.

149. Stadelmann, B.; Hanevik, K.; Andersson, M.K.; Bruserud, O.; Svard, S.G. The role of arginine and arginine-metabolizing enzymes during Giardia-Host cell interactions in vitro. BMC Microbiol. 2013, doi:10.1186/1471-2180-13-256.

150. Mokrzycka, M.; Kolasa, A.; Kosierkiewicz, A.; Wiszniewska, B. Inducible nitric oxide synthase in duodenum of children with Giardia lamblia infection. Folia Histochem. Cytobiol. 2010, 48, 191-196.

151. MacMicking, J.D.; Nathan, C.; Hom, G.; Chartrain, N.; Fletcher, D.S.; Trumbauer, M.; Stevens, K.; Xie, Q.W.; Sokol, K.; Hutchinson, N.; et al. Altered responses to bacterial infection and endotoxic shock in mice lacking inducible nitric oxide synthase. Cell 1995, 81, 641-650.

152. McCafferty, D.M.; Mudgett, J.S.; Swain, M.G.; Kubes, P. Inducible nitric oxide synthase plays a critical role in resolving intestinal inflammation. Gastroenterology 1997, 112, 1022-1027.

153. McCafferty, D.M.; Miampamba, M.; Sihota, E.; Sharkey, K.A.; Kubes, P. Role of inducible nitric oxide synthase in trinitrobenzene sulphonic acid induced colitis in mice. Gut 1999, 45, 864-873.

154. Beck, P.L.; Xavier, R.; Wong, J.; Ezedi, I.; Mashimo, H.; Mizoguchi, A.; Mizoguchi, E.; Bhan, A.K.; Podolsky, D.K. Paradoxical roles of different nitric oxide synthase isoforms in colonic injury. Am. J. Physiol. Gastrointest. Liver Physiol. 2004, 286, G137-G147.

155. Krieglstein, C.F.; Cerwinka, W.H.; Laroux, F.S.; Salter, J.W.; Russell, J.M.; Schuermann, G.; Grisham, M.B.; Ross, C.R.; Granger, D.N. Regulation of murine intestinal inflammation by reactive metabolites of oxygen and nitrogen: Divergent roles of superoxide and nitric oxide. J. Exp. Med. 2001, 194, 1207-1218.

156. Resta-Lenert, S.; Barrett, K.E. Enteroinvasive bacteria alter barrier and transport properties of human intestinal epithelium: Role of inos and cox-2. Gastroenterology 2002, 122, 1070-1087.

157. Skinn, A.C.; MacNaughton, W.K. Nitric oxide inhibits camp-dependent cftr trafficking in intestinal epithelial cells. Am. J. Physiol. Gastrointest. Liver Physiol. 2005, 289, G739-G744.

158. Ashida, H.; Ogawa, M.; Kim, M.; Mimuro, H.; Sasakawa, C. Bacteria and host interactions in the gut epithelial barrier. Nat. Chem. Biol. 2012, 8, 36-45. 
159. Ashida, H.; Mimuro, H.; Ogawa, M.; Kobayashi, T.; Sanada, T.; Kim, M.; Sasakawa, C. Cell death and infection: A double-edged sword for host and pathogen survival. J. Cell Biol. 2011, 195, 931-942.

160. Kim, M.; Ashida, H.; Ogawa, M.; Yoshikawa, Y.; Mimuro, H.; Sasakawa, C. Bacterial interactions with the host epithelium. Cell Host Microbe 2010, 8, 20-35.

161. Buret, A.G.; Bhargava, A. Modulatory mechanisms of enterocyte apoptosis by viral, bacterial and parasitic pathogens. Crit. Rev. Microbiol. 2014, 40, 1-17.

162. Carneiro, L.A.; Travassos, L.H.; Soares, F.; Tattoli, I.; Magalhaes, J.G.; Bozza, M.T.; Plotkowski, M.C.; Sansonetti, P.J.; Molkentin, J.D.; Philpott, D.J.; et al. Shigella induces mitochondrial dysfunction and cell death in nonmyleoid cells. Cell Host Microbe 2009, 5, $123-136$.

163. Paesold, G.; Guiney, D.G.; Eckmann, L.; Kagnoff, M.F. Genes in the Salmonella pathogenicity island 2 and the Salmonella virulence plasmid are essential for Salmonella-induced apoptosis in intestinal epithelial cells. Cell. Microbiol. 2002, 4, 771-781.

164. Kim, J.M.; Eckmann, L.; Savidge, T.C.; Lowe, D.C.; Witthoft, T.; Kagnoff, M.F. Apoptosis of human intestinal epithelial cells after bacterial invasion. J. Clin. Investig. 1998, 102, 1815-1823.

165. Clark, C.S.; Maurelli, A.T. Shigella flexneri inhibits staurosporine-induced apoptosis in epithelial cells. Infect. Immun. 2007, 75, 2531-2539.

166. Faherty, C.S.; Maurelli, A.T. Spa15 of shigella flexneri is secreted through the type iii secretion system and prevents staurosporine-induced apoptosis. Infect. Immun. 2009, 77, 5281-5290.

167. Alm, K.; Oredsson, S. Cells and polyamines do it cyclically. Essays Biochem. 2009, 46, 63-76.

168. Solaymani-Mohammadi, S.; Singer, S.M. Regulation of intestinal epithelial cell cytoskeletal remodeling by cellular immunity following gut infection. Mucosal Immunol. 2013, 6, 369-378.

169. Reuther, J.Y.; Baldwin, A.S., Jr. Apoptosis promotes a caspase-induced amino-terminal truncation of ikappabalpha that functions as a stable inhibitor of nf-kappab. J. Biol. Chem. 1999, 274, 20664-20670.

170. Kim, K.W.; Kim, B.J.; Chung, C.W.; Jo, D.G.; Kim, I.K.; Song, Y.H.; Kwon, Y.K.; Woo, H.N.; Jung, Y.K. Caspase cleavage product lacking amino-terminus of ikappabalpha sensitizes resistant cells to tnf-alpha and trail-induced apoptosis. J. Cell. Biochem. 2002, 85, 334-345.

171. Kang, K.H.; Lee, K.H.; Kim, M.Y.; Choi, K.H. Caspase-3-mediated cleavage of the nf-kappa b subunit p65 at the nh2 terminus potentiates naphthoquinone analog-induced apoptosis. J.Biol. Chem. 2001, 276, 24638-24644.

172. Iwasaki, A.; Medzhitov, R. Toll-like receptor control of the adaptive immune responses. Nat. Immunol. 2004, 5, 987-995.

173. Reis e Sousa, C. Dendritic cells in a mature age. Nat. Rev. Immunol. 2006, 6, 476-483.

174. Rescigno, M.; Urbano, M.; Valzasina, B.; Francolini, M.; Rotta, G.; Bonasio, R.; Granucci, F.; Kraehenbuhl, J.P.; Ricciardi-Castagnoli, P. Dendritic cells express tight junction proteins and penetrate gut epithelial monolayers to sample bacteria. Nat. Immunol. 2001, 2, 361-367.

175. Chieppa, M.; Rescigno, M.; Huang, A.Y.; Germain, R.N. Dynamic imaging of dendritic cell extension into the small bowel lumen in response to epithelial cell tlr engagement. J. Exp. Med. 2006, 203, 2841-2852. 
176. Kamda, J.D.; Singer, S.M. Phosphoinositide 3-kinase-dependent inhibition of dendritic cell interleukin-12 production by Giardia lamblia. Infect. Immun. 2009, 77, 685-693.

177. Lee, H.Y.; Kim, J.; Noh, H.J.; Kim, H.P.; Park, S.J. Giardia lamblia binding immunoglobulin protein triggers maturation of dendritic cells via activation of tlr4-myd88-p38 and erk1/2 mapks. Parasite Immunol. 2014, 36, 627-646.

178. Obendorf, J.; Renner Viveros, P.; Fehlings, M.; Klotz, C.; Aebischer, T.; Ignatius, R. Increased expression of $\mathrm{cd} 25, \mathrm{~cd} 83$, and $\mathrm{cd} 86$, and secretion of il-12, il-23, and il-10 by human dendritic cells incubated in the presence of toll-like receptor 2 ligands and Giardia duodenalis. Parasit Vectors 2013, doi:10.1186/1756-3305-6-317.

179. Banik, S.; Renner Viveros, P.; Seeber, F.; Klotz, C.; Ignatius, R.; Aebischer, T. Giardia duodenalis arginine deiminase modulates the phenotype and cytokine secretion of human dendritic cells by depletion of arginine and formation of ammonia. Infect. Immun. 2013, 81, 2309-2317.

180. Grit, G.H.; Devriendt, B.; van Coppernolle, S.; Geurden, T.; Hope, J.; Vercruysse, J.; Cox, E.; Geldhof, P.; Claerebout, E. Giardia duodenalis stimulates partial maturation of bovine dendritic cells associated with altered cytokine secretion and induction of t-cell proliferation. Parasite Immunol. 2014, 36, 157-169.

181. Gordon, S. Alternative activation of macrophages. Nat. Rev. Immunol. 2003, 3, 23-35.

182. Mantovani, A.; Sica, A.; Sozzani, S.; Allavena, P.; Vecchi, A.; Locati, M. The chemokine system in diverse forms of macrophage activation and polarization. Trends Immunol. 2004, 25, 677-686.

183. Mills, C.D.; Kincaid, K.; Alt, J.M.; Heilman, M.J.; Hill, A.M. M-1/m-2 macrophages and the th1/th2 paradigm. J. Immunol. 2000, 164, 6166-6173.

184. Martinez, F.O.; Gordon, S. The $\mathrm{m} 1$ and $\mathrm{m} 2$ paradigm of macrophage activation: Time for reassessment. F1000Prime Rep. 2014, doi: 10.12703/P6-13.

185. Maloney, J.; Keselman, A.; Li, E.; Singer, S.M. Macrophages expressing arginase 1 and nitric oxide synthase 2 accumulate in the small intestine during Giardia lamblia infection. Microbes Infect. 2015, 17, 462-467.

186. Dorman, S.E.; Holland, S.M. Interferon-gamma and interleukin-12 pathway defects and human disease. Cytokine Growth Factor Rev. 2000, 11, 321-333.

187. Jouanguy, E.; Doffinger, R.; Dupuis, S.; Pallier, A.; Altare, F.; Casanova, J.L. Il-12 and ifn-gamma in host defense against mycobacteria and Salmonella in mice and men. Curr. Opin. Immunol. 1999, $11,346-351$.

188. Lathrop, S.K.; Binder, K.A.; Starr, T.; Cooper, K.G.; Chong, A.; Carmody, A.B.; Steele-Mortimer, O. Replication of Salmonella enterica serovar Typhimurium in human monocyte-derived macrophages. Infect. Immun. 2015, 83, 2661-2671.

189. Pesce, J.T.; Ramalingam, T.R.; Mentink-Kane, M.M.; Wilson, M.S.; El Kasmi, K.C.; Smith, A.M.; Thompson, R.W.; Cheever, A.W.; Murray, P.J.; Wynn, T.A. Arginase-1-expressing macrophages suppress th2 cytokine-driven inflammation and fibrosis. PLoS Pathog. 2009, doi:10.1371/journal.ppat.1000371.

190. Salgame, P.; Yap, G.S.; Gause, W.C. Effect of helminth-induced immunity on infections with microbial pathogens. Nat. Immunol. 2013, 14, 1118-1126. 
191. Boef, A.G.; May, L.; van Bodegom, D.; van Lieshout, L.; Verweij, J.J.; Maier, A.B.; Westendorp, R.G.; Eriksson, U.K. Parasitic infections and immune function: Effect of helminth infections in a malaria endemic area. Immunobiology 2013, 218, 706-711.

192. Mengesha, B.; Endris, M.; Takele, Y.; Mekonnen, K.; Tadesse, T.; Feleke, A.; Diro, E. Prevalence of malnutrition and associated risk factors among adult visceral leishmaniasis patients in northwest ethiopia: A cross sectional study. BMC Res. Notes 2014, 7, 75.

193. Adamu, H.; Wegayehu, T.; Petros, B. High prevalence of diarrhoegenic intestinal parasite infections among non-art HIV patients in fitche hospital, ethiopia. PLoS ONE 2013, doi:10.1371/journal.pone.0072634.

194. Boaitey, Y.A.; Nkrumah, B.; Idriss, A.; Tay, S.C. Gastrointestinal and urinary tract pathogenic infections among HIV seropositive patients at the komfo anokye teaching hospital in ghana. BMC Res Notes 2012, doi:10.1186/1756-0500-5-454.

195. Sanyaolu, A.O.; Oyibo, W.A.; Fagbenro-Beyioku, A.F.; Gbadegeshin, A.H.; Iriemenam, N.C. Comparative study of entero-parasitic infections among hiv sero-positive and sero-negative patients in lagos, nigeria. Acta Trop. 2011, 120, 268-272.

(C) 2015 by the authors; licensee MDPI, Basel, Switzerland. This article is an open access article distributed under the terms and conditions of the Creative Commons Attribution license (http://creativecommons.org/licenses/by/4.0/). 